\title{
Recent Advances in Palladium-Catalyzed Bridging C-H Activation by Using Alkenes, Alkynes or Diazo Compounds as Bridging Reagents
}

\author{
Fulin Zhang ${ }^{\diamond a}$ \\ Luoting Xin ${ }^{\diamond b}$ \\ Yinghua $\mathrm{Yu}^{\mathrm{b}}$ \\ Saihu Liao ${ }^{* a}$ \\ Xueliang Huang*b (i) \\ a Key Laboratory for Molecule Synthesis and Function Discov- \\ ery (Fujian Province University), College of Chemistry, Fu- \\ zhou University, Fuzhou 350116, P. R. of China \\ shliao@fzu.edu.cn \\ ${ }^{b}$ Key Laboratory of Coal to Ethylene Glycol and Its Related \\ Technology, Center for Excellence in Molecular Synthesis, \\ Fujian Institute of Research on the Structure of Matter, Fuji \\ an College, University of Chinese Academy of Sciences, \\ Chinese Academy of Sciences, Fuzhou, Fujian 350002, \\ P. R. of China \\ huangxl@fjirsm.ac.cn \\ ${ }^{\bullet}$ These authors contributed equally
}

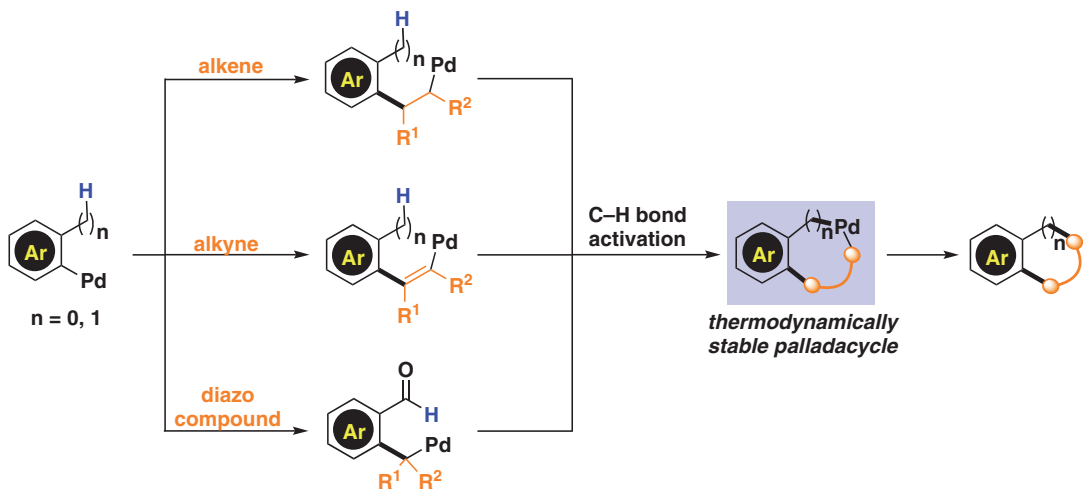

Dedicated to the 60th anniversary of the Fujian Institute of Research on the Structure of Matter

Received: 05.06.2020

Accepted after revision: 04.08.2020

Published online: 22.09 .2020

DOI: 10.1055/s-0040-1707268; Art ID: ss-2020-m0310-sr

\begin{abstract}
Transition-metal-catalyzed direct inert $\mathrm{C}-\mathrm{H}$ bond functionalization has attracted much attention over the past decades. However, because of the high strain energy of the suspected palladacycle generated via $\mathrm{C}-\mathrm{H}$ bond palladation, direct functionalization of a $\mathrm{C}-\mathrm{H}$ bond less than a three-bond distance from a catalyst center is highly challenging. In this short review, we summarize the advances on palladiumcatalyzed bridging $\mathrm{C}-\mathrm{H}$ activation, in which an inert proximal $\mathrm{C}-\mathrm{H}$ bond palladation is promoted by the elementary step of migratory insertion of an alkene, an alkyne or a metal carbene intermediate.

1 Introduction

2 Palladium-Catalyzed Alkene Bridging $\mathrm{C}-\mathrm{H}$ Activation

2.1 Intramolecular Reactions

2.2 Intermolecular Reactions

3 Palladium-Catalyzed Alkyne Bridging $\mathrm{C}-\mathrm{H}$ Activation

3.1 Intermolecular Reactions

3.2 Intramolecular Reactions

4 Palladium-Catalyzed Carbene Bridging $\mathrm{C}-\mathrm{H}$ Activation

5 Conclusion and Outlook
\end{abstract}

Key words palladium catalysis, bridging $\mathrm{C}-\mathrm{H}$ activation, alkenes, alkynes, diazo compounds, migratory insertion

\section{Introduction}

Transition-metal-catalyzed direct inert $\mathrm{C}-\mathrm{H}$ bond functionalization has been recognized as a concise method to construct molecules with diverse functionalities from read-

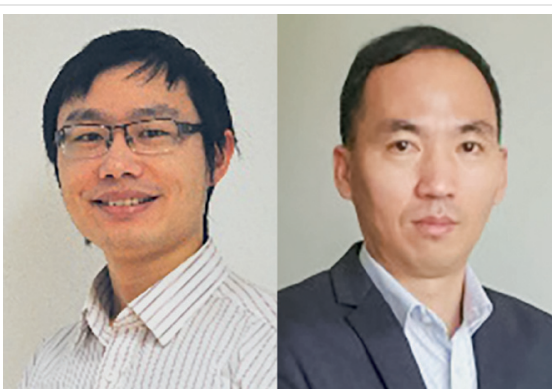

Saihu Liao (left) was born in Hunan, China. After the completion of his bachelor and master's studies in Yuefa Gong's group at Huazhong University of Science and Technology, he began his studies as a doctoral candidate in 2007 under the guidance of Professor Benjamin List at the Max-Planck-Institut für Kohlenforschung, Germany. He obtained his Ph.D. in organic chemistry in 2011, and he then returned to China to join Prof. Yong Tang's group at the Shanghai Institute of Organic Chemistry as a research associate. In September 2016, he started his independent research at Fuzhou University and was promoted to full professor in 2017. His current research interests include photocatalytic transformations, asymmetric catalysis, and organocatalytic polymerization.

Xueliang Huang (right) was born in Hunan, China. After graduating in chemistry from Hunan University of Science and Technology in 2003, he received his M.Sc. degree at Nankai University under the supervision of Prof. Shihua Wu in 2006. He completed his Ph.D. studies in 2009 under the supervision of Prof. Song Ye at the Institute of Chemistry, Chinese Academy of Sciences. After postdoctoral studies with Prof. Nuno Maulide at the Max-Planck-Institut für Kohlenforschung, Germany, he was appointed as a professor at Fujian Institute of Research on the Structure of Matter, Chinese Academy of Sciences. His current research interests are focused on the development of new synthetic methods involving transition metals. 
ily accessible chemicals. ${ }^{1}$ Mechanistically, among established reaction modes, directing-group-enabled $\mathrm{C}-\mathrm{H}$ bond activation through the formation of a thermodynamically stable metallacycle has gained much attention. ${ }^{2}$ However, this process remains largely limited to $\mathrm{C}-\mathrm{H}$ bonds that are located three bonds away from the directing atom because of the preferential formation of five-membered (or larger) metallacycles. In this context, the direct transformation of a $\mathrm{C}-\mathrm{H}$ bond located in a close proximal position is challenging, ${ }^{3}$ as the formation of small and strained metallacycles is energetically unfavorable. Migratory insertion is a fundamental step that occurs in many transition-metal-catalyzed reactions, and a longer bridging arm can be created after this elementary step. This short review will focus specifically on palladium-catalyzed bridging $\mathrm{C}-\mathrm{H}$ activation, which provides viable solutions for the functionalization of inert $\mathrm{C}-\mathrm{H}$ bonds that are located in close proximity. Herein, we summarize the advances in this area. Mechanistic rationale, synthetic potential, scope and limitations are included. The reactions are classified according to the bridging reagents employed: (1) palladium-catalyzed alkene bridging $\mathrm{C}-\mathrm{H}$ activation, (2) palladium-catalyzed alkyne bridging $\mathrm{C}-$ $\mathrm{H}$ activation, and (3) palladium-catalyzed carbene bridging $\mathrm{C}-\mathrm{H}$ activation. Palladium and norbornene/norbornadiene co-catalyzed functionalization of (hetero)arenes ${ }^{4}$ and alkenes ${ }^{5}$ is a prominent example of alkene bridging $\mathrm{C}-\mathrm{H}$ activation. Related work on these topics has already been discussed in recent reviews. ${ }^{6}$

\section{Palladium-Catalyzed Alkene Bridging C-H Activation}

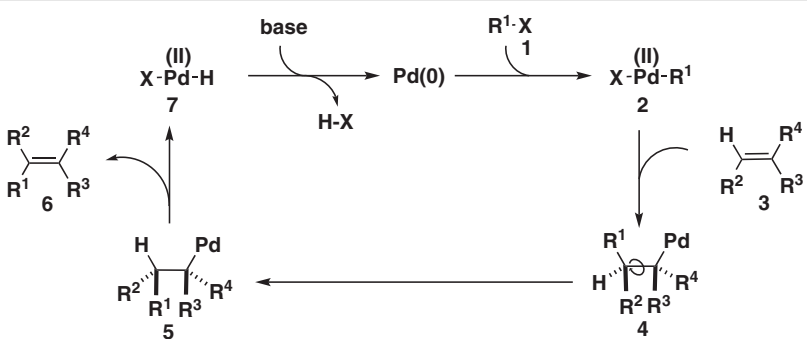

Scheme 1 Simplified mechanism for the palladium-catalyzed Heck reaction

Alkenes are ubiquitous feedstock chemicals which have found broad applications by the synthetic community. The palladium-catalyzed arylation or alkenylation of alkenes is referred to as the Heck reaction, a simplified catalytic cycle of which is displayed in Scheme 1. Oxidative addition of a low-valent palladium catalyst to an organic (pseudo)halide $\mathbf{1}$ affords intermediate $\mathbf{2}$. Coordination of $\mathbf{2}$ to olefin $\mathbf{3}$, followed by syn-migratory insertion gives adduct 4. Adjusting to the proper configuration by $\mathrm{C}-\mathrm{C}$ bond rotation in 4 furnishes 5. Next, syn- $\beta$-hydride elimination gives a new sub- stituted alkene $\mathbf{6}$ and releases the palladium hydride species 7. Reductive elimination of $\mathbf{7}$ closes the catalytic cycle and regenerates the active catalyst.

When a syn-hydride is not available, the synthetic intermediate $\mathbf{5}$ can be trapped by other reagents. In this context, a variety of cascade reactions initiated by Heck-type migratory insertion have been developed in the past decades. ${ }^{7}$ The progress made on palladium-catalyzed $\mathrm{C}-\mathrm{C}$ double migratory insertion enabling functionalization of a proximal $\mathrm{C}-\mathrm{H}$ bond is summarized in the following section.

\subsection{Intramolecular Reactions}

By employing bifunctional compounds 8 as reactants, Larock and co-workers achieved the synthesis of fused polycyclic compounds 9 (Scheme 2). ${ }^{8}$ From a mechanistic viewpoint, intramolecular migratory insertion of the $\mathrm{C}-\mathrm{C}$ double bond in intermediate $\mathbf{1 0}$ can be considered as the alkene bridging process $(\mathbf{1 0} \rightarrow \mathbf{1 1})$, which is crucial for the following 1,4-palladium translocation ${ }^{9}$ through the fivemembered palladacycle 12. A subsequent intramolecular $\mathrm{C}-\mathrm{H}$ bond palladation would give intermediate 14 , which upon reductive elimination eventually affords the polycyclic product 9. Obviously, the creation of a bridging arm through intramolecular alkene migratory insertion is critical for the subsequent two-fold $\mathrm{C}-\mathrm{H}$ bond activation. This intriguing cascade reaction offers a concise method to construct complex molecules from easily accessible reactants.

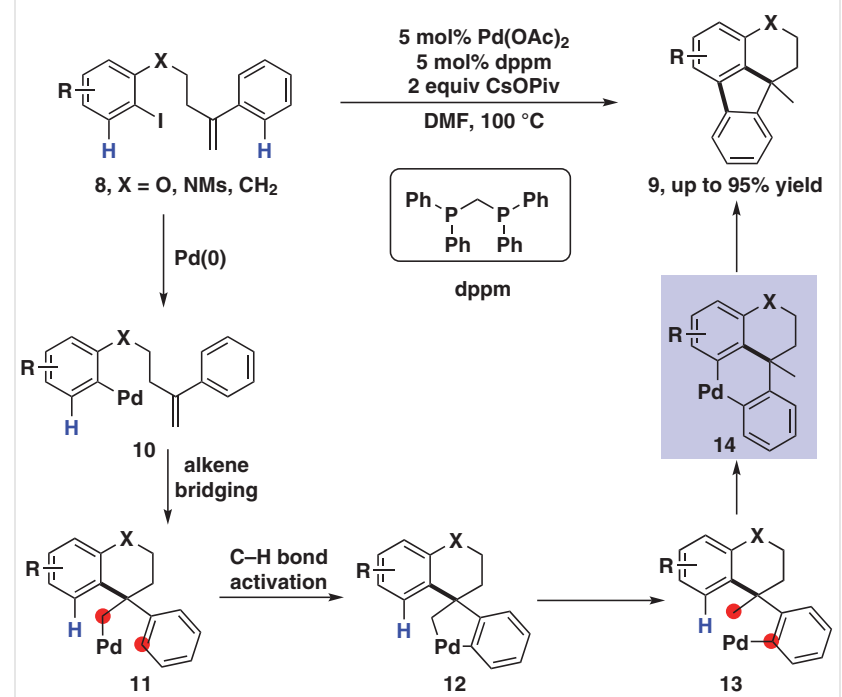

Scheme 2 Larock's 1,4-palladium shift initiated by intramolecular alkene bridging $\mathrm{C}-\mathrm{H}$ activation

According to a similar principle, several transformations based on alkene migratory insertion via a 1,4-palladium shift/intramolecular $\mathrm{C}-\mathrm{H}$ bond functionalization were reported recently. For example, Zhu and co-workers have applied this strategy for fused oxindole synthesis. ${ }^{10}$ As de- 
picted in Scheme 3, the reaction was initiated by oxidative addition of 15. Intramolecular migratory insertion of the $\alpha, \beta$-unsaturated double bond could accomplish the alkene bridging process to give intermediate $\mathbf{1 8}$, which possessed a suitable configuration for the following 1,4-Pd shift to furnish 19 or 20. Selective $C\left(s p^{3}\right)-H\left(R^{1}=M e\right)$ or $C\left(s p^{2}\right)-H\left(R^{1}=\right.$ $\mathrm{H})$ bond activation and reductive elimination then gives fused oxindoles $\mathbf{1 6}$ or $\mathbf{1 7}$, respectively. Of note, a $\mathrm{C}\left(\mathrm{sp}^{3}\right)-\mathrm{H}$ bond activation was preferred to form seven-membered palladacycles $\left(\mathrm{R}^{1}=\mathrm{Me}\right.$ and $\mathrm{R}^{2}=$ aryl $)$. A related transformation from 21 into 22 was also demonstrated by Loh and $\mathrm{Xu} .{ }^{11}$ They found that the regioselectivity could be altered by the substituents on the double bond.

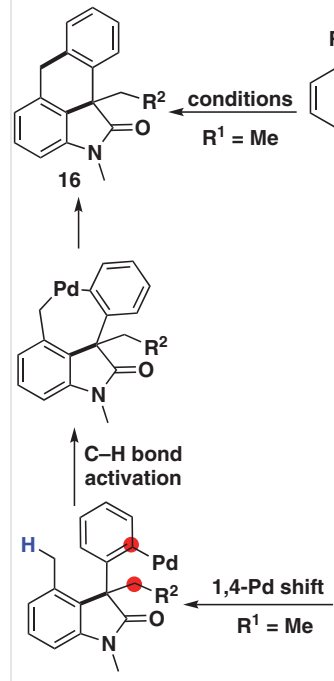

19
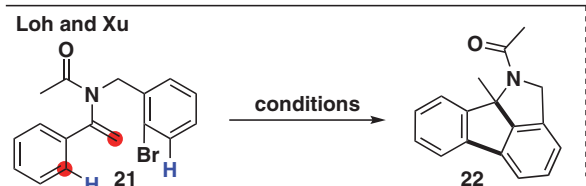

conditions

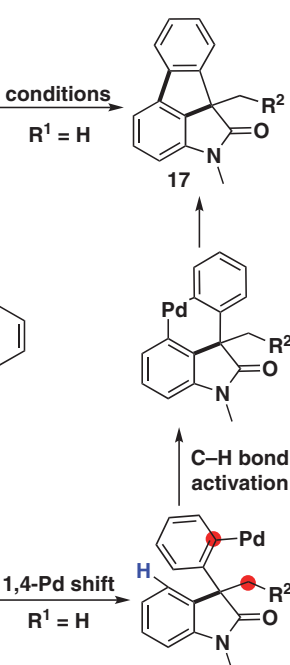

20

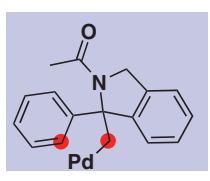

Scheme 3 Palladium-catalyzed synthesis of fused oxoindoles through an intramolecular alkene bridging 1,4-Pd shift and $\mathrm{C}-\mathrm{H}$ bond arylation

The five-membered palladacycle generated through intramolecular alkene bridging $\mathrm{C}-\mathrm{H}$ activation could be trapped by a range of external reagents under appropriate conditions. In 2010, Jia and co-workers reported a watercontrolled regioselective alkene bridging $\mathrm{C}-\mathrm{H}$ functionalization. ${ }^{12}$ According to their deuterium labeling experiments, alkene bridging $\mathrm{C}-\mathrm{H}$ activation occurred to produce a five-membered palladacycle 26. At this stage, addition of water led to a regioselective protonation to give product $\mathbf{2 4}$ with the functional group located on the methylene carbon atom. Whereas without adding water as the co-solvent, functionalization of the phenyl ring to give $\mathbf{2 5}$ was observed. In this reaction, several nucleophiles, including $\mathrm{K}_{4}\left[\mathrm{Fe}(\mathrm{CN})_{6}\right] \cdot 3 \mathrm{H}_{2} \mathrm{O}$, styrene, methyl acrylate, unactivated ole-

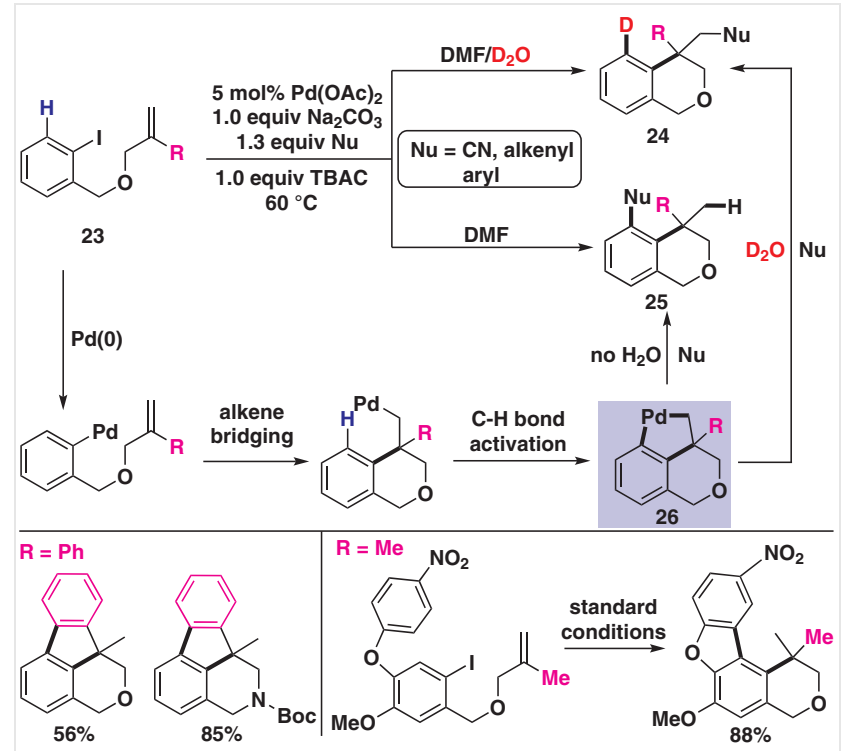

Scheme 4 Water-controlled palladium-catalyzed regioselective alkene bridging $\mathrm{C}-\mathrm{H}$ bond functionalization

fins and aryl boronic acids, could react with compound 23. When DMF was employed as the solvent, a sequence involving alkene migratory insertion enabled a 1,4-palladium shift/intramolecular arylation to occur to give polycyclic products in moderate to high yields (Scheme 4).

In 2014, Lautens and co-workers demonstrated that the palladium(II) intermediate generated by intramolecular alkene bridging $\mathrm{C}-\mathrm{H}$ activation could react with a variety of (hetero)aryl iodides to produce fused biaryls $\mathbf{2 7}$ with high structural complexity (Scheme 5). ${ }^{13}$ Compared with Jia's work, ${ }^{12}$ they found that five-membered palladacycle $\mathbf{2 6}$
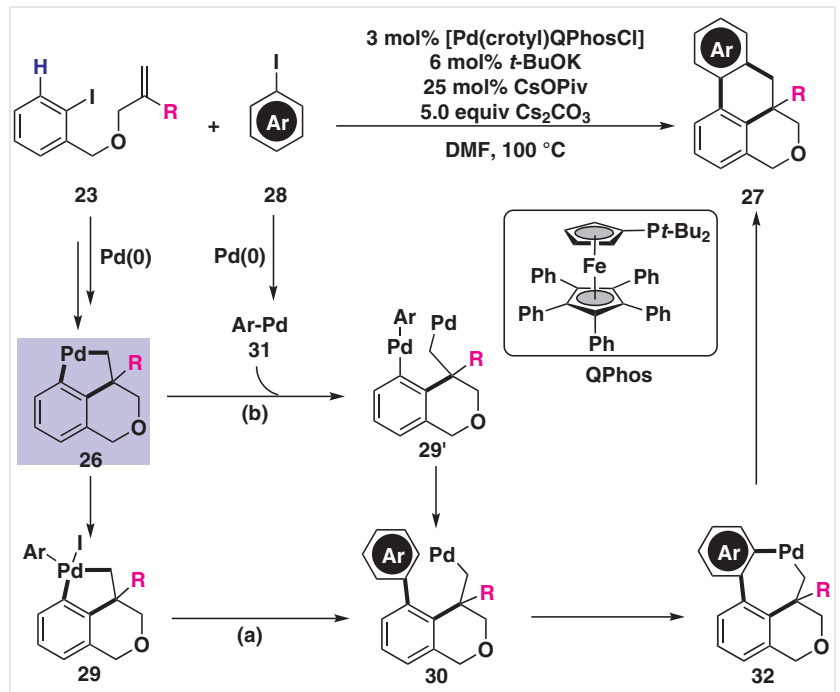

Scheme 5 Palladium-catalyzed synthesis of fused biaryl compounds through intramolecular alkene bridging $\mathrm{C}-\mathrm{H}$ activation 
could be functionalized at both positions connected to palladium atom. Employment of the complex [Pd(crotyl)QPhosCl] as the precatalyst was essential to suppress formation of the by-product arising from dimerization of $\mathbf{2 8}$.

According to the results they obtained, two plausible pathways were proposed. For path a, oxidative addition of palladacycle $\mathbf{2 6}$ to aryl iodide $\mathbf{2 8}$ might give the palladium(IV) intermediate $\mathbf{2 9}$, which upon aryl-aryl reductive elimination could generate intermediate $\mathbf{3 0}$. As an alternative pathway, transmetalation might occur between $\mathbf{2 6}$ and intermediate $\mathbf{3 1}$ to give the bis-palladium(II) intermediate 29'. Aryl-aryl reductive elimination in $\mathbf{2 9}$ ' would also furnish 30 (path b, Scheme 5). At this stage, an intramolecular arylation occurring through a seven-membered palladacycle 32 would afford the fused biaryl products 27 . A related reaction was reported by $\mathrm{Li}$ and co-workers in 2016 by employing the simple palladium salt $\left[\mathrm{Pd}(\operatorname{cod}) \mathrm{Cl}_{2}\right]$ as the precatalyst. ${ }^{14}$ Yang and Liang have applied this strategy for oxindole synthesis, and two aryl groups derived from $\mathbf{2 8}$ were incorporated in the final products. ${ }^{15}$ In their subsequent study, Lautens and co-workers found that intermediate $\mathbf{2 6}$ could be trapped by $\mathrm{Me}_{6} \mathrm{Si}_{2}$ or $\mathrm{Me}_{6} \mathrm{Ge}_{2}$, thus disilylation or digermanylation of $\mathbf{2 3}$ could be easily realized. ${ }^{16 a}$ Shortly after this study, Liang and Yang reported a palladium-catalyzed domino Heck-disilylation and borylation of alkenetethered 2-(2-halophenyl)- $1 H$-indoles. ${ }^{16 b}$

Yao $^{17}$ and Lautens ${ }^{18}$ have explored the reactivity of a five-membered palladacycle toward arynes. Similar to the catalytic cycle displayed in Scheme 5, the palladium intermediate generated through intramolecular alkene bridging $\mathrm{C}-\mathrm{H}$ activation could react with benzyne to form a sevenmembered palladacycle akin to $\mathbf{3 2}$. Reductive elimination would then give the fused products. As depicted in Scheme 6 , a range of polycyclic products was obtained in moderate to high yields.

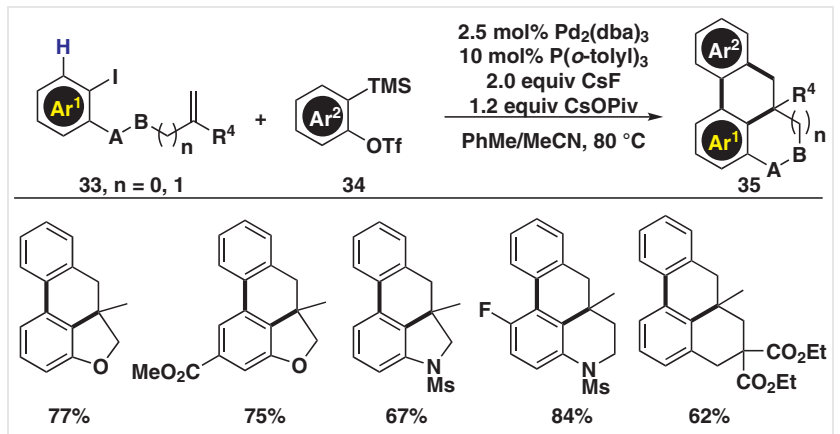

Scheme 6 Palladium-catalyzed intramolecular alkene bridging $\mathrm{C}-\mathrm{H}$ activation and aryne insertion

Very recently, Yang and Liang reported a new method for the synthesis of fused isoquinolinediones and isoquinolinones through a cascade reaction of compounds $\mathbf{3 6}$ with 2-bromobenzoic acid (37) (Scheme 7, top). ${ }^{19}$ Mechanistical- ly, a Heck-type cyclization of $\mathbf{3 6}$ in presence of a suitable palladium catalyst could accomplish the alkene bridging process. The generation of a two-atom bridging arm would facilitate the proximal $\mathrm{C}-\mathrm{H}$ bond palladation to furnish a fused five-membered palladacycle 39. Oxidative addition of 39 and $\mathbf{3 7}$ led to the formation of a spiro palladium(IV) intermediate $\mathbf{4 0}$. A consecutive reductive elimination and decarboxylation then gave another seven-membered palladacycle 41. The final isoquinolinedione or isoquinolinone products were produced via reductive elimination of $\mathbf{4 1}$. The carbonyl group in $\mathbf{3 6}$ was crucial for this domino process to occur (Scheme 7, bottom). As depicted, the preparation of fused benzofuran or oxindole derivatives from substrates $\mathbf{4 2 a}$-d failed when using this reaction.

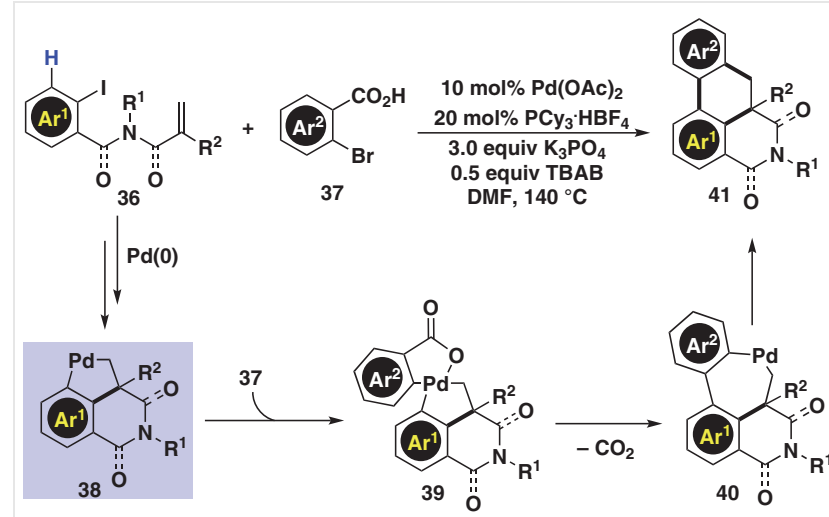
failed substrates<smiles>C=C(C)CN(C)Cc1ccccc1I</smiles>
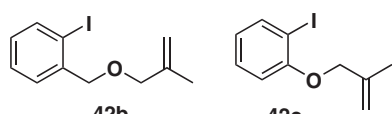

$42 b$

42c

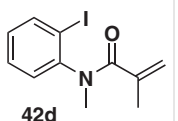

Scheme 7 Palladium-catalyzed intramolecular alkene bridging $\mathrm{C}-\mathrm{H}$ activation and decarboxylation

In their subsequent studies, Lautens and co-workers described a regioselective insertion of an unsymmetrical alkyne into the five-membered palladacycle 47 . The utilization of a phosphine ligand, $\mathrm{P}\left(2-\mathrm{F}_{3} \mathrm{C}-\mathrm{C}_{6} \mathrm{H}_{4}\right)_{3}$, with the right balance of both electronic and steric characters was critical to achieve high efficiency. By contrast, the reaction using the electron-neutral ligand $\mathrm{PPh}_{3}$ resulted in no conversion of the both reactants 43 and 44 , and when $\mathrm{P}(0 \text {-tol })_{3}$ was used as the ligand, low conversion was observed. Similarly, the $\sigma$-alkyl palladium species $\mathbf{4 6}$ was produced via an intramolecular Heck-type cyclization. The elongation of a twoatom bridging arm could deliver the palladium catalyst close to the $\mathrm{C}\left(\mathrm{sp}^{2}\right)-\mathrm{H}$ bond, thus furnishing a thermodynamically stable palladacycle 47 . After a sequence of coordination, migratory insertion of $\mathbf{4 4}$ and reductive elimination, products 45 were obtained regioselectively (Scheme $8) .{ }^{20}$ For the reactant 43 , an alkyl group was always situated at the $\alpha$-position relative to the carbonyl group $(R=$ alkyl). 
According to Lautens' previous work, replacement of the alkyl substituent with an aryl group switched the chemoselectivity to produce a spirooxindole. ${ }^{21}$
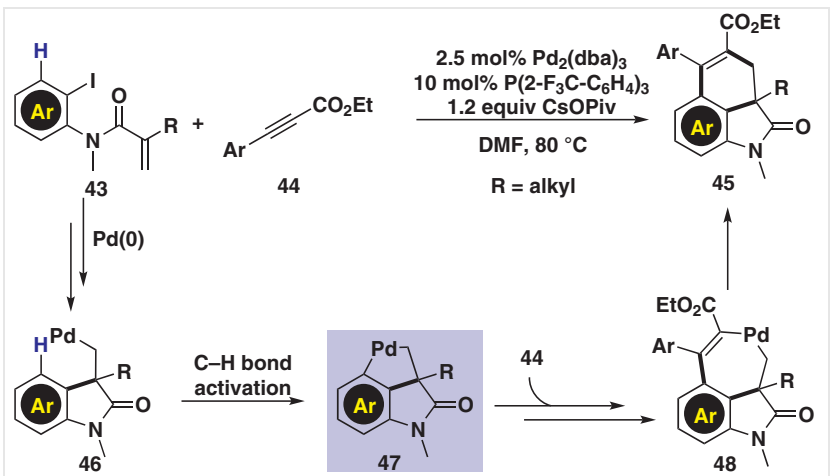

Scheme 8 Palladium-catalyzed intramolecular alkene bridging $\mathrm{C}-\mathrm{H}$ activation and alkyne insertion

In 2014, Shi and co-workers found that the palladacycle $\mathbf{2 6}$ could react with di-tert-butyldiaziridinone (49) to form a spiro palladium(IV) intermediate 51. After releasing one equivalent of tert-butyl isocyanate, indolines $\mathbf{5 0}$ bearing a tert-butyl group could be obtained (Scheme 9). ${ }^{22}$ In this reaction, a nitrene intermediate $\mathbf{5 2}$ was probably involved. In analogy with the work of Lautens (see Scheme 8), when the alkyl substituent $(\mathrm{R}=$ alkyl) on the olefin was replaced by an aryl group, a spiroindoline was obtained selectively.

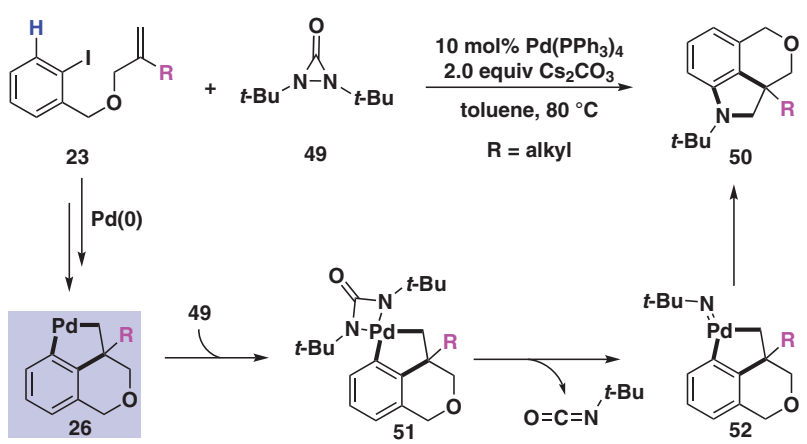

Scheme 9 Palladium-catalyzed intramolecular alkene bridging $\mathrm{C}-\mathrm{H}$ activation and formal nitrene insertion

\subsection{Intermolecular Reactions}

The main obstacle in developing palladium-catalyzed intermolecular alkene bridging $\mathrm{C}-\mathrm{H}$ activation lies in the facile $\beta$-hydride elimination to form substituted olefins. As mentioned previously, when a syn- $\beta$-hydrogen atom is not available, the $\sigma$-alkyl palladium(II) intermediate could participate in the following cascade reactions. Based on this principle, studies on reactions mediated by palladium and norbornene (or its analogues) have attracted significant attention. As shown in Scheme 10, the formation of the five- membered palladacycle $\mathbf{5 4}$ is promoted by Heck-type migratory insertion of a palladium(II) intermediate with norbornene (53). This type of transformation, which is referred to as the Catellani reaction, is an important example of palladium-catalyzed alkene bridging $\mathrm{C}-\mathrm{H}$ activation. Due to space limitations and the fact that related advances having been discussed in recent elegant reviews, ${ }^{6}$ we will focus on reactions employing olefins other than norbornene-type alkenes in this section.

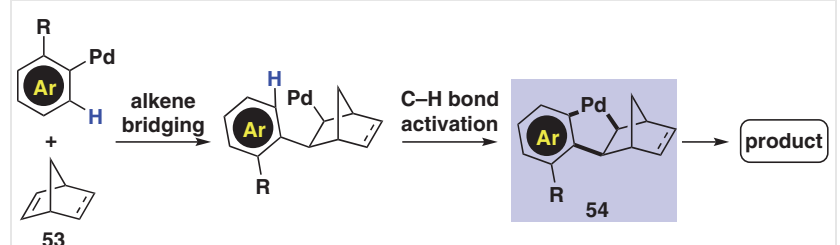

Scheme 10 Simplified reaction mode of the Catellani reaction

In 2001, Carretero and co-workers discovered the first palladium-catalyzed cascade arylation of an acyclic alkene when they tested the activity of $\beta$-substituted vinylsulfone 55 with phenyl iodide (28a), (Scheme 11, top). ${ }^{23}$ According to their systematic examination of the reaction conditions, they found that the utilization of $\mathrm{Ag}_{2} \mathrm{CO}_{3}$ as the base, a sulfone-containing $\alpha, \beta$-unsaturated alkene and an excess amount of 28a were important to achieve high selectivity to form dihydrophenanthrenes $\mathbf{5 6}$ instead of the normal
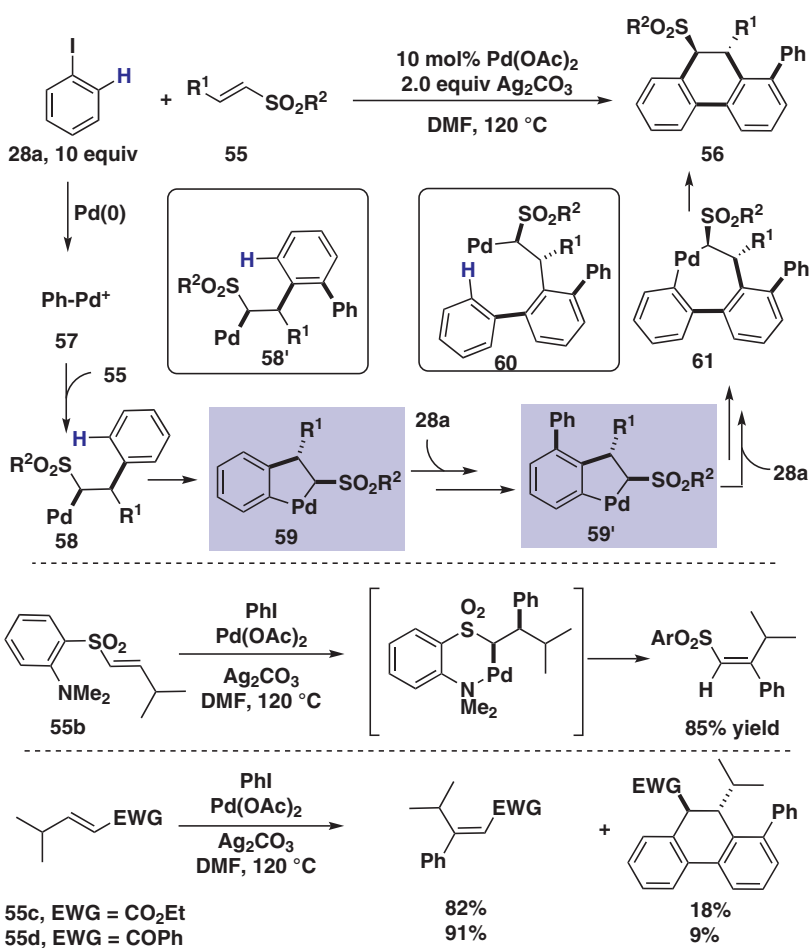

Scheme 11 Palladium-catalyzed intermolecular alkene bridging $\mathrm{C}-\mathrm{H}$ activation using a vinylsulfone as the bridging reagent 
Heck-type products. As can be seen, this reaction was quite efficient for bond formation as four new $\mathrm{C}-\mathrm{C}$ bonds were created in a single step. Mechanistically, oxidative addition of the palladium(0) catalyst to phenyl iodide in the presence of $\mathrm{Ag}_{2} \mathrm{CO}_{3}$ would give the cationic phenylpalladium(II) intermediate $\mathbf{5 7}$. Next, syn-insertion of $\mathbf{5 5}$ into $\mathbf{5 7}$ would afford sulfonylalkylpalladium intermediate $\mathbf{5 8}$, thereby accomplishing the alkene bridging process. The cationic nature of $\mathbf{5 8}$ might account for the fast $\mathrm{C}-\mathrm{H}$ activation to produce the five-membered palladacycle 59. Intermediate 59 then reacts with a second equivalent of phenyl iodide to give another cationic $\sigma$-sulfonylalkylpalladium species $\mathbf{5 8}$. The repetition of the same mechanistic sequence would lead to the formation of intermediates $\mathbf{5 9}^{\prime}$ and $\mathbf{6 0}$. A third $\mathrm{C}-\mathrm{H}$ bond activation could give the seven-membered palladacycle 61, and reductive elimination of $\mathbf{6 1}$ would eventually afford the product $\mathbf{5 6}$. The critical role played by the cationic nature of the palladium species was evidenced by the reaction of vinylsulfone $\mathbf{5 5 b}$ with $\mathbf{2 8 a}$ under the standard conditions, which gave the normal Heck product exclusively (Scheme 11, middle). Replacing the sulfonyl group with an ester or ketone group also led to a switch of the chemoselectivity (Scheme 11, bottom).

An elegant palladium-catalyzed alkene bridging $\mathrm{C}-\mathrm{H}$ activation using other olefins as bridging reagents was reported by Wang and Hu. According to their studies, a variety of substituted 1,6-dienes $\mathbf{6 2}$ could be successfully applied as modular bridging arms to react with different aryl halides 28, achieving selective ortho- $\mathrm{C}\left(\mathrm{sp}^{2}\right)-\mathrm{H}$ bond activation of aryl halides $\mathbf{2 8}$. The selectivity toward the cascade reaction sequence that outcompeted with the traditional Heck reaction is noteworthy, and which might be attributed to the existence of the second alkenyl tether that could easily participate in cascade syn migratory insertion, and further promote the intramolecular $\mathrm{C}-\mathrm{H}$ bond palladation to furnish a thermodynamically stable seven-membered palladacycle 66. Reductive elimination of $\mathbf{6 6}$ could give the final polycyclic products 63 (Scheme 12). ${ }^{24}$ In this reaction, 1,6-diene 62 was involved in a two-fold migratory insertion of a palladium(II) species (64 and 65), acting as a modular fouratom bridging reagent to facilitate the cascade reaction. As depicted, different protecting groups $\left(R^{1}\right)$, substituents on the alkene termini ( $\mathrm{R}^{3}$ and $\mathrm{R}^{4}$ ) and functional groups on the phenyl ring $(\mathrm{Ar})$ were compatible with the current cascade reaction, and the corresponding polycyclic products were obtained in moderate to excellent yields.
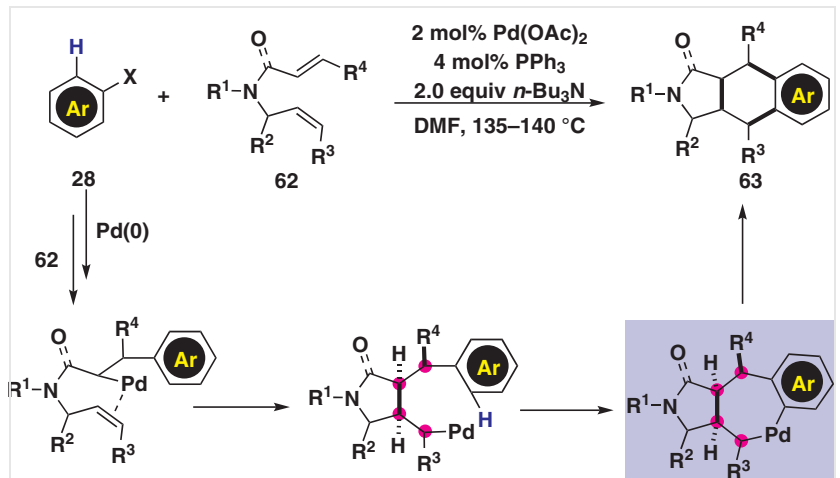

64
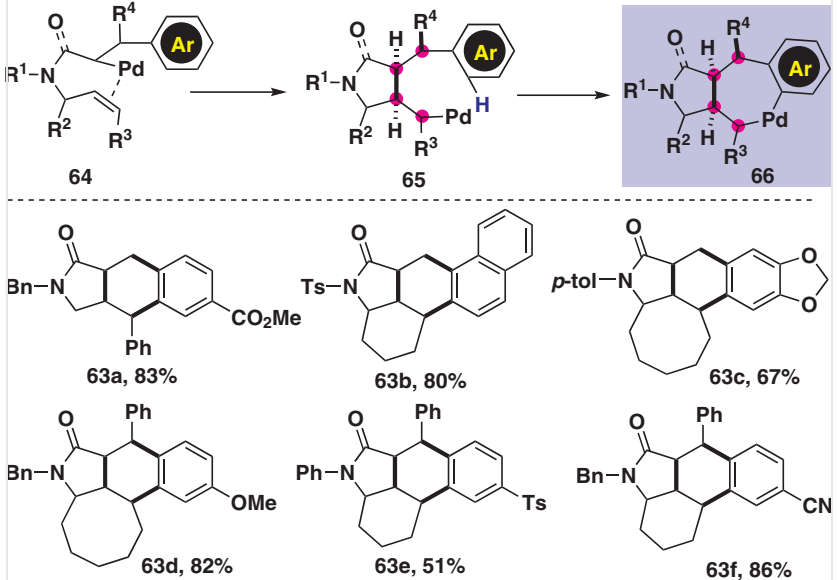

Scheme 12 Palladium-catalyzed intermolecular alkene bridging $\mathrm{C}-\mathrm{H}$ activation using 1,6-dienes as the bridging reagents

In 2005, Ohno and Tanaka demonstrated that enallenes could participate in palladium-catalyzed bridging $\mathrm{C}-\mathrm{H}$ bond arylation reactions. They found that different (hetero)-aryl halides $\mathbf{2 8}$ could participate in the cascade cyclization reaction with substituted enallenes $\mathbf{6 7}$, and that the presence of a substituent on the alkene terminus $\left(R^{2}\right)$ was essential to inhibit the undesired $\beta-\mathrm{H}$ elimination to form the Hecktype products. Based on their findings, two reaction modes were proposed to explain the stereoselectivity of the reaction (Scheme 13). ${ }^{25}$

\section{Palladium-Catalyzed Alkyne Bridging C-H Activation}

Alkynes have been frequently used as substrates for palladium-catalyzed carbopalladation reactions. These types of reactions normally involve following general steps (Scheme 14). First, oxidative addition of a low-valent palladium catalyst to a suitable organic halide leads to the formation of a palladium(II) species 71. Subsequently, this organometallic species reacts with alkynes through a syn carbopalladation pathway to generate a vinyl palladium(II) intermediate $\mathbf{7 2}$. Herein, we refer to the syn migratory insertion of the alkyne to $\mathbf{7 1}$ to generate the vinyl palladium(II) species 72 as the alkyne bridging process. The trapping of $\mathbf{7 2}$ by appropriate reagents leads to the formation of a variety of functional products. 

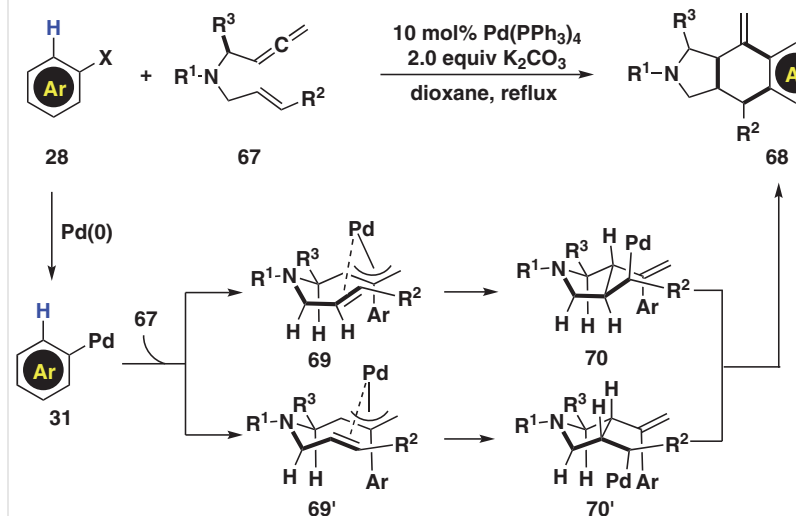

Scheme 13 Palladium-catalyzed intermolecular alkene bridging $\mathrm{C}-\mathrm{H}$ activation using enallenes as the bridging reagents

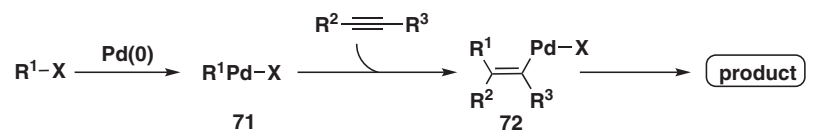

Scheme 14 The syn carbopalladation of alkynes

\subsection{Intermolecular Reactions}

In 1989, Heck reported the preparation of 2,3-diphenylindenone via a palladium-catalyzed coupling of $o$-iodobenzaldehyde with diphenylacetylene. ${ }^{26}$ Following this report, Larock and co-workers re-examined this reaction and expanded the scope to produce a broader range of indenone derivatives 75 (Scheme 15). ${ }^{27}$ In analogy to the aforementioned alkene bridging $\mathrm{C}-\mathrm{H}$ activation, the reaction was proposed to be initiated by oxidative addition of a $\operatorname{Pd}(0)$ species to aryl halide $\mathbf{7 3}$ to generate aryl palladium(II) intermediate 76, which could further react with alkyne $\mathbf{7 4}$ to accomplish the alkyne bridging process and produce intermediate 77. Intramolecular $\mathrm{C}-\mathrm{H}$ bond palladation of the aldehyde moiety would furnish a six-membered palladacycle 78. Reductive elimination of $\mathbf{7 8}$ then affords substituted indenones 75 (Scheme 15, top). This process was highly regioselective for alkynes containing tertiary alkyl or other hindered groups, with the major isomer bearing the more sterically demanding group at the 2-position of the indenone. When less hindered alkynes were employed, the corresponding products were obtained with low regioselectivity. Recently, Satyanarayana and Ramesh identified that by using L-proline as a ligand, this reaction could be carried out in aqueous medium. The excellent regioselectivity allowed this reaction to serve as a key step in the synthesis of a neolignan (Scheme 15, bottom). ${ }^{28}$
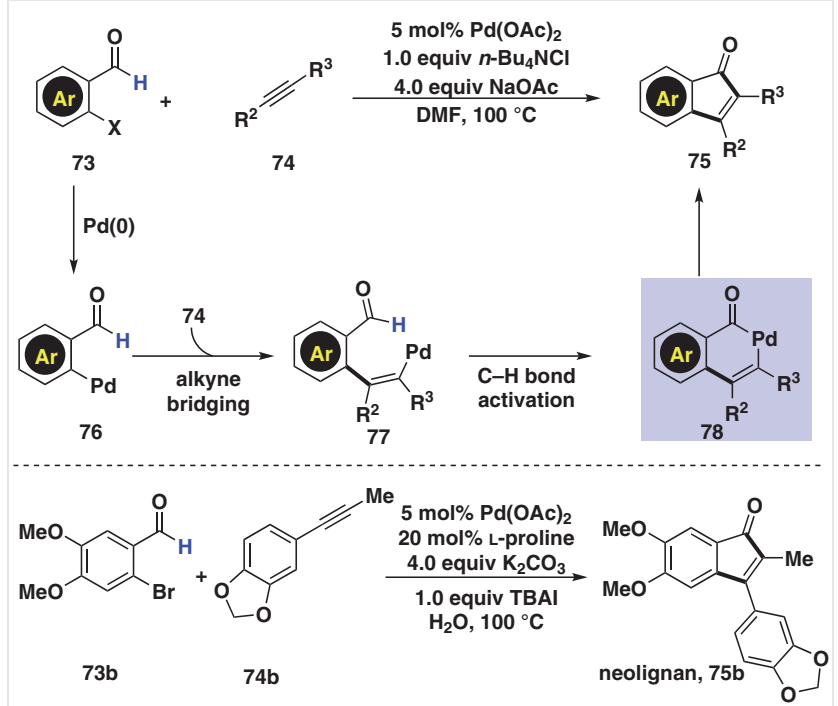

Scheme 15 Palladium-catalyzed intermolecular alkyne bridging $\mathrm{C}-\mathrm{H}$ activation for indenone synthesis

In addition to alkynes, arynes are also competent bridging reagents that participate in Pd-catalyzed annulations. Larock and co-workers reported a Pd-catalyzed annulation of arynes with $\boldsymbol{o}$-haloarenecarboxaldehydes $\mathbf{7 3}$ to provided fluoren-9-ones 80 in good yields. ${ }^{29}$ Arynes were produced in situ through the reaction of 2-(trimethylsilyl)aryl triflates 79 with CsF. A plausible pathway is depicted in Scheme 16 . The reaction of the $\operatorname{Pd}(0)$ catalyst with the aryne formed in situ from $\mathbf{7 9}$ afforded palladacycle $\mathbf{8 1}$, which could further react with aryl halide $\mathbf{7 3}$ to furnish the $\mathrm{Pd}(\mathrm{IV})$ intermediate $\mathbf{8 2}$. Reductive elimination of $\mathbf{8 2}$ would then give arylpalladium(II) intermediate 83. Intramolecular $\mathrm{C}-\mathrm{H}$ bond activation of the aldehyde moiety would furnish a six-membered palladacycle 84. However, the authors could not rule out a pathway in which the $\operatorname{Pd}(0)$ catalyst inserts directly into the $\mathrm{C}-\mathrm{X}$ bond of aryl halide $\mathbf{7 3}$ to form intermediate $\mathbf{7 6}$ (see Scheme 15), which then undergoes carbopalladation of the aryne to give rise to $\mathbf{8 3}$. Reductive elimination of $\mathbf{8 4}$ would give fluoren-9-ones 80. Interestingly, the reaction of 3-methoxybenzyne exhibited very high regioselectivity, and 1-methoxyfluoren-9-one was obtained as the major product. The high regioselectivity might be attributed to the directing effect arising from weak coordination of the methoxy group to the palladium atom in 82. Thus Pd appeared to add to the more hindered end of the triple bond of the aryne formed in situ from $\mathbf{7 9}$. 

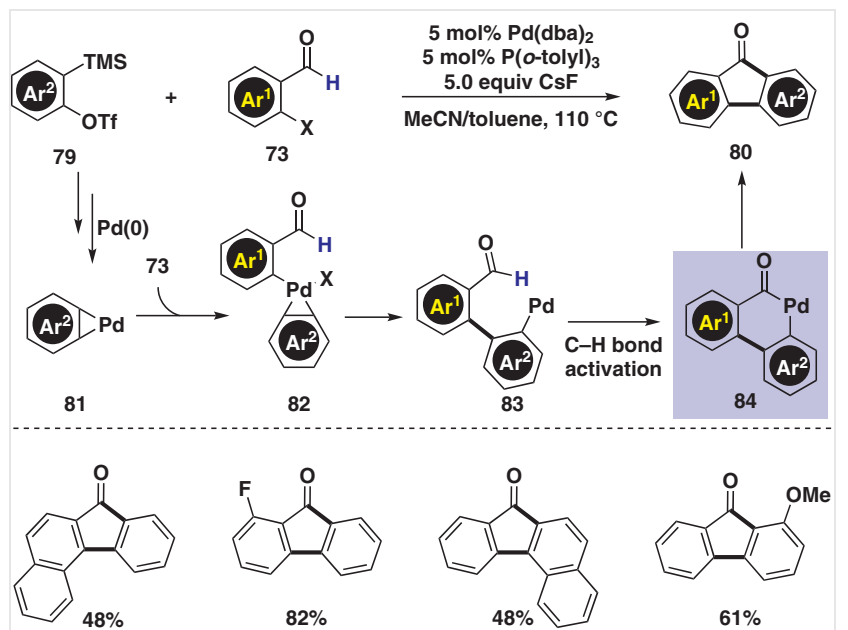

$61 \%$

Scheme 16 Palladium-catalyzed intermolecular alkyne bridging $\mathrm{C}-\mathrm{H}$ activation using an aryne as the bridging reagent

Sakakibara, ${ }^{30}$ Heck $^{26}$ and Miura ${ }^{31}$ have reported reactions on the palladium-catalyzed annulation of simple aryl halides with internal alkynes to give tetrasubstituted naphthalenes 85. Interestingly, the chemoselectivities could be altered by slightly modifying the reaction conditions (Scheme 17). Accordingly, Heck and co-workers found that the reaction of phenyl iodide $\mathbf{2 8 a}$ with diphenylacetylene 74a using a catalyst generated from $\mathrm{Pd}(\mathrm{OAc})_{2}$ and $\mathrm{PPh}_{3}$ in nitromethane could give 1,2,3,4-tetraphenylnaphthalene (85a) in $47 \%$ yield. By contrast, Dyker and co-workers found that the major product could be switched to 9,10-diphenylphenanthrene (86) by using simple $\mathrm{Pd}(\mathrm{OAc})_{2}$ as the catalyst and DMF as the solvent. ${ }^{32}$ More intriguingly, in 2000, Larock and co-workers reported that the annulation of aryl iodide $\mathbf{2 8 a}$ and diphenylacetylene 74a provided fluorene 87 under similar conditions, albeit using $\mathrm{NaOAc}$ as the additive. ${ }^{33}$

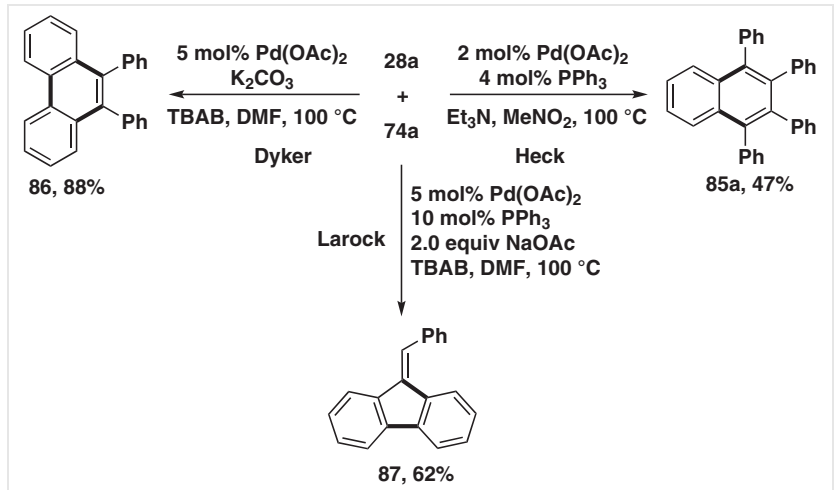

Scheme 17 Divergent syntheses of carbocyclic products through palladium-catalyzed intermolecular alkyne bridging $\mathrm{C}-\mathrm{H}$ activation

As is already known, the palladium-catalyzed reaction of aryl halides $\mathbf{2 8}$ with alkynes $\mathbf{7 4}$ could lead to the direct formation of a potential five-membered palladacycle 88. Trap- ping intermediate $\mathbf{8 8}$ with appropriate reagents could give a range of products with rich structural diversity (Scheme 18).

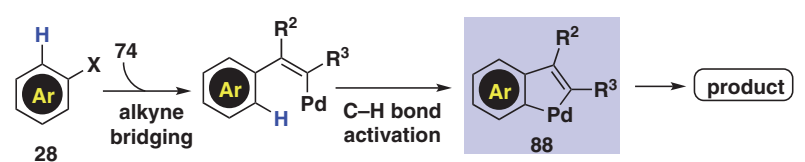

Scheme 18 Palladium-catalyzed intermolecular alkyne bridging $\mathrm{C}-\mathrm{H}$ activation for the formation of a five-membered palladacycle

Hexamethyldisilane is commercially available and has been widely employed as a trimethylsilyl source in organosilicon chemistry. Zhang and co-workers reported that the addition of hexamethyldisilane into palladacyclic species $\mathbf{8 8}$ could afford a range of vinylsilanes $\mathbf{8 9}$ (Scheme 19, a). ${ }^{34}$ The same group also discovered that intermediate $\mathbf{8 8}$ could be trapped by di-tert-butyldiaziridinone $\mathbf{4 9}$ to give substituted indoles $\mathbf{9 0}$ bearing a tert-butyl group on the nitrogen atom (Scheme 19, b). ${ }^{35}$ More recently, Habibi and Jafarpour used simple and readily accessible anilines as nitrogen sources to react with palladacycle $\mathbf{8 8}$, giving $N$-aryl-substituted indoles $\mathbf{9 0}^{\prime}$ in a highly efficient manner (Scheme 19, c). ${ }^{36}$ By using $\mathrm{CH}_{2} \mathrm{Br}_{2}$ as the reaction partner, Zhang and co-workers uncovered a valuable method for the preparation of benzofulvenes $\mathbf{9 1}$ through the alkylation of intermediate $\mathbf{8 8}$ (Scheme 19, d). ${ }^{37}$ Using this novel protocol as a platform, Liang and Yang developed a simple and convenient approach for the construction of phenanthrene frameworks 92 via a palladium-catalyzed domino alkyne insertion/C-H activation/decarboxylation sequence (Scheme 19, e). ${ }^{38}$

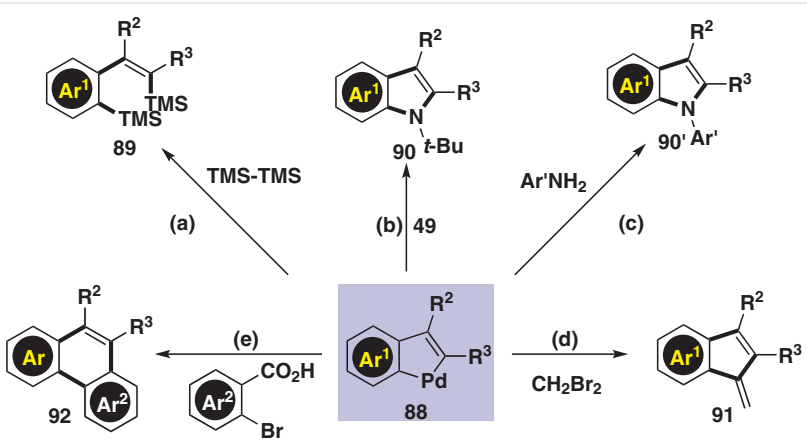

Scheme 19 Trapping palladacycle 88 with different electrophiles

In 2003, during an exploration on the palladium-catalyzed reactions of aryl iodides with internal alkynes for the synthesis of tetrasubstituted naphthalenes 85, Miura and co-workers found that the reaction of 1-iodonaphthalene (28b) with diethyl acetylenedicarboxylate (74b) gave dieth$\mathrm{yl}$ acenaphthylene-1,2-dicarboxylate (93a) as the major product (Scheme 20, top). ${ }^{31}$ Recently, Yamamoto and coworkers described a similar formal [3+2] annulation by using 4-iodo-2-quinolone $\mathbf{2 8 c}$ as the reactant. They found that 
slow addition of the activated alkyne 74c could suppress the formation of the [2+2+2] annulation product effectively without adding phosphine ligands. ${ }^{39}$ In analogy to the aforementioned work, alkyne $\mathbf{7 4 c}$ acted as a bridging reagent to facilitate formation of the six-membered palladacycle 94 via an intramolecular C-H bond activation. Reductive elimination of $\mathbf{9 4}$ then afforded product $\mathbf{9 3 b}$ (Scheme 20, bottom).
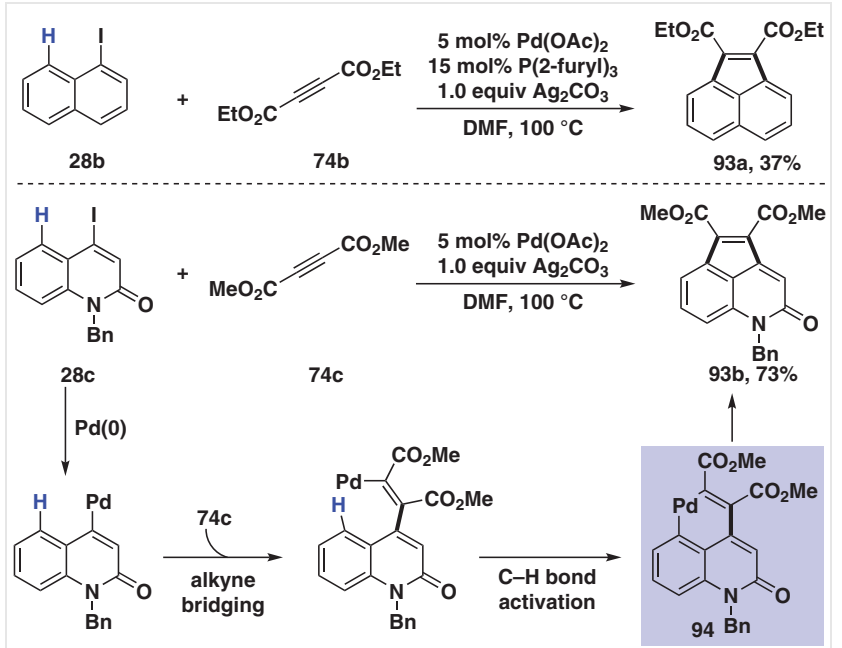

Scheme 20 Palladium-catalyzed intermolecular alkyne bridging $\mathrm{C}-\mathrm{H}$ activation by using an activated internal alkyne as the bridging reagent

During their studies on the palladium-catalyzed annulation of arynes with 2-halobiaryls, ${ }^{40}$ Larock and co-workers discovered that the reaction of ethyl 4-iodobenzoate (28d) with two equivalents of the aryne $\mathbf{7 9} \mathbf{b}^{\prime}$, derived from 4,5dimethyl-2-(trimethylsilyl)phenyl trifluoromethanesulfonate $(\mathbf{7 9 b})$, gave the corresponding substituted triphenylene 95b in 50\% yield. As depicted in Scheme 21, this reaction probably proceeds through an aryne-bridging $\mathrm{C}-\mathrm{H}$ activation pathway. ${ }^{41}$

As consequence of studies in the area of through space 1,4-palladium shifts, ${ }^{33}$ Larock and co-workers have demonstrated a consecutive vinylic to aryl to allylic palladium migration via alkyne bridging $\mathrm{C}-\mathrm{H}$ activation. ${ }^{42}$ Taking the reaction of aryl iodide $\mathbf{2 8 e}$ with internal alkyne $\mathbf{7 4 d}$ as a specific example, the first 1,4-palladium migration (vinylic $\rightarrow$ aryl) was proposed to proceed through the five-membered palladacycle 88e. The second 1,4-palladium migration (aryl $\rightarrow$ allylic) could furnish the $\eta_{3}$-allyl palladium intermediate 97. Addition of a pivalate anion to $\mathbf{9 7}$ gave the final allylic pivalate product $\mathbf{9 6}$ as a mixture of $E / Z$ isomers (Scheme 22, top). According to a report from Larock and co-workers, such an alkyne bridging 1,4-palladium shift strategy could be applied for the synthesis of substituted carbazoles, indoles, and dibenzofurans (Scheme 22, bottom) ${ }^{43}$

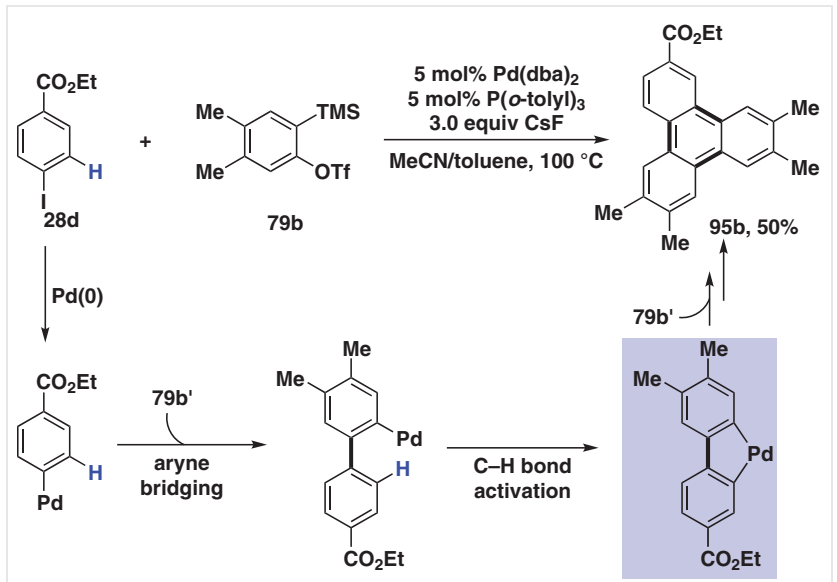

Scheme 21 Palladium-catalyzed aryne bridging $\mathrm{C}-\mathrm{H}$ activation for triphenylene synthesis

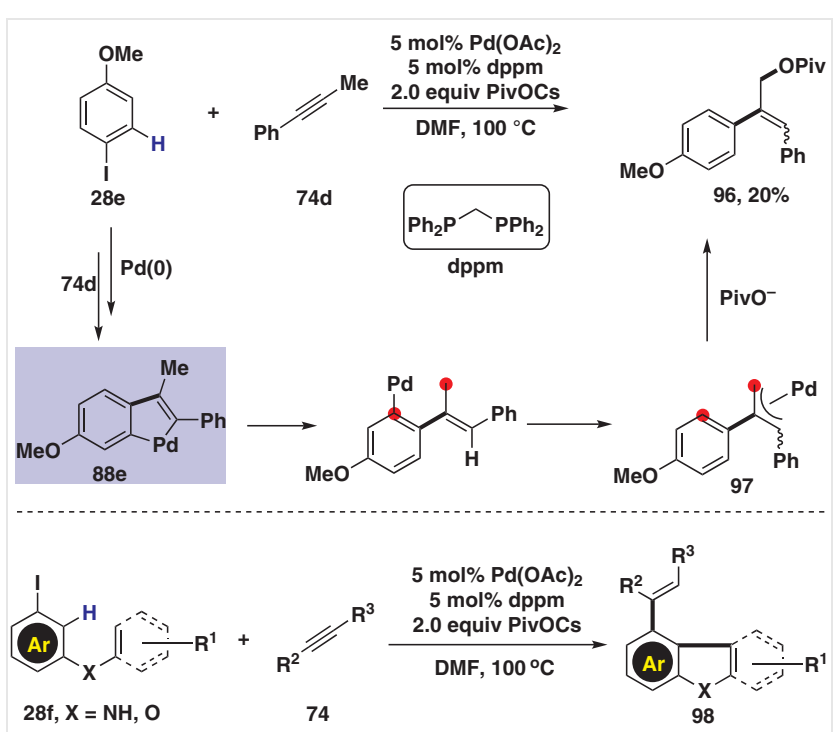

Scheme 22 An alkyne bridging 1,4-palladium shift strategy

Very recently, Xie's group described a palladium-catalyzed highly selective bifunctionalization of 3-iodo-o-carborane $(\mathbf{9 9})$ through alkyne bridging palladium migration (Scheme 23). ${ }^{44}$ Accordingly, the syn insertion of alkyne 74a into intermediate $\mathbf{1 0 1}$ could facilitate $\mathrm{B}-\mathrm{H}$ bond activation to furnish palladacycle 103. The transformation from 102 $\rightarrow \mathbf{1 0 3} \rightarrow \mathbf{1 0 4}$ can be considered as a 1,4-palladium shift process. Reductive elimination of $\mathbf{1 0 4}$ could then complete the difunctionalization of $\mathbf{9 9}$. Interestingly, product $\mathbf{1 0 0}$ could be trapped in situ by addition of a Grignard reagent. Thus dicarbofunctionalization of $\mathbf{9 9}$ could be achieved in a straightforward manner.

In 2019, Yao and co-workers reported a palladium-catalyzed reaction of 1-iodo-3-[(2-methylallyl)oxy]benzene $(\mathbf{2 8 g})$ with a range of internal alkynes $\mathbf{7 4}$. The tethered alkenyl moiety in aryl iodide $\mathbf{2 8 g}$ could insert into the tran- 


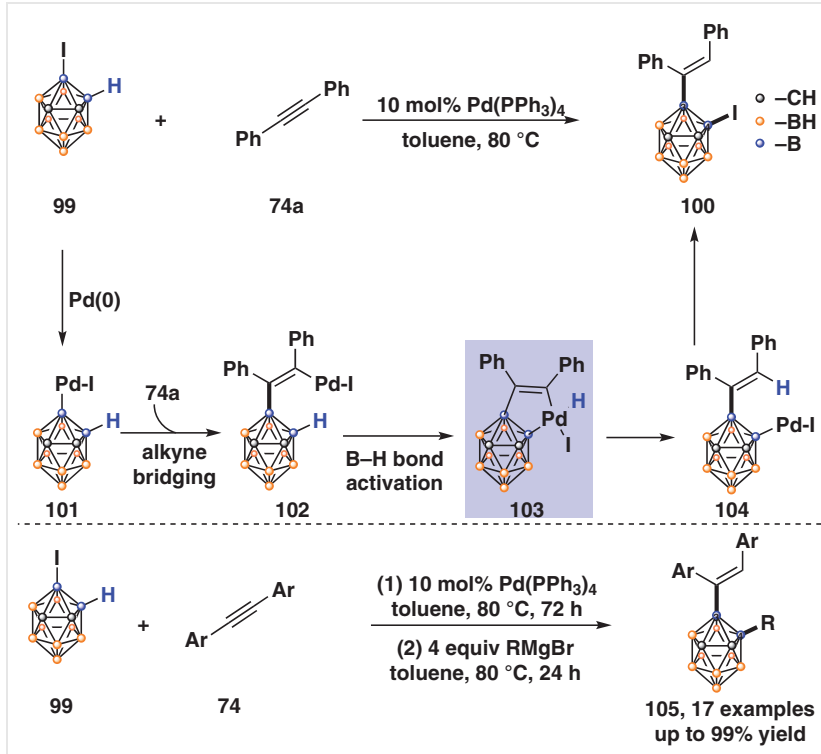

Scheme 23 Palladium-catalyzed bifunctionalization of 3-iodo-o-carborane through intermolecular alkyne bridging $\mathrm{B}-\mathrm{H}$ activation

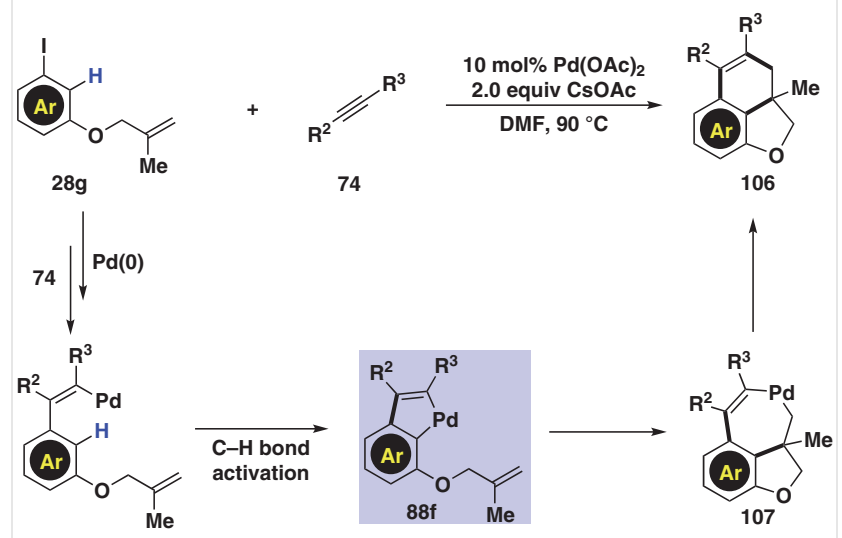

Scheme 24 A cascade reaction through palladium-catalyzed intermolecular alkyne bridging $\mathrm{C}-\mathrm{H}$ activation and intramolecular alkene insertion

sient five-membered palladacycle $\mathbf{8 8 f}$, which was generated through alkyne bridging $\mathrm{C}-\mathrm{H}$ activation. Reductive elimination of the resulting seven-membered palladacycle $\mathbf{1 0 7}$ resulted in the fused polycyclic products 106 (Scheme 24). Kinetic isotope effect (KIE, $K_{\mathrm{H}} / K_{\mathrm{D}}=2.3$ ) experiments indicated that cleavage of the $\mathrm{C}\left(\mathrm{sp}^{2}\right)-\mathrm{H}$ bond might be involved in the rate-determining step. ${ }^{45}$
Akin to simple internal alkynes, 1,6-diynes 108 could also serve as bridging reagents to promote proximal inert C-H bond activation. In 2010, Hu and co-workers reported an efficient protocol for the preparation of polysubstituted aromatics 109. Mechanistically, two-fold syn migratory insertion of palladium(II) species $\mathbf{3 1}$ could complete the diyne bridging process to give the vinyl palladium(II) species $\mathbf{1 1 0}$. Intramolecular $\mathrm{C}-\mathrm{H}$ bond activation could afford a sevenmembered palladacycle 111, which upon reductive elimination would furnish the final product $\mathbf{1 0 9}$. The whole process was very efficient for the formation of multiple bonds, and a broad range of polyaromatic compounds was obtained in moderate to high yields (Scheme 25). ${ }^{46}$

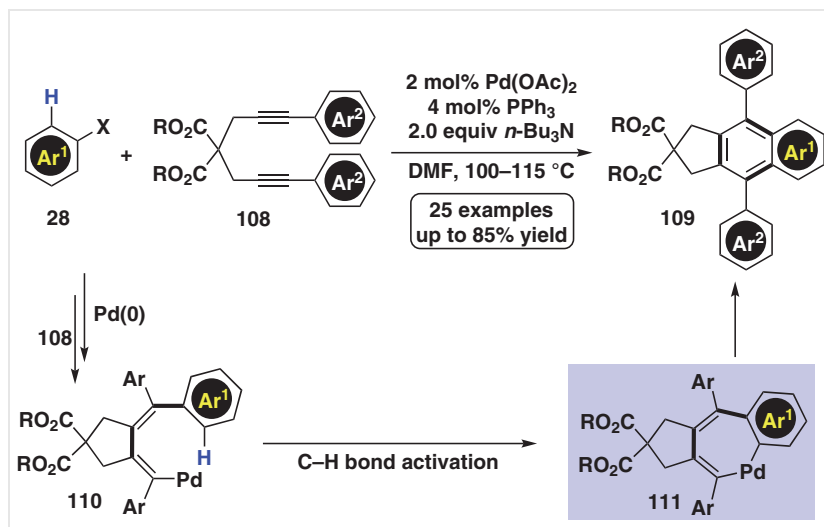

Scheme 25 Palladium-catalyzed alkyne bridging $\mathrm{C}-\mathrm{H}$ activation using 1,6-diynes as the bridging reagents

\subsection{Intramolecular Reactions}

The introduction of a tethered alkyne moiety into organic halides can greatly enhance the structural complexity of the corresponding products. For example, in 2005, Suffert and Bour reported a tin-reagent-dependent palladiumcatalyzed cascade reaction, in which an intramolecular alkyne bridging $\mathrm{C}\left(\mathrm{sp}^{2}\right)-\mathrm{H}$ bond heteroarylation, allylation and vinylation were observed. ${ }^{47}$ To understand the mechanism, the authors prepared deuterium labeled diol 112- $\mathbf{D}_{\mathbf{1}}$. When a vinyl tin reagent was employed, a product was obtained in which vinylation took place at the ipso position of the deuterium atom on the phenyl ring, and in which the deuterium atom was completely transferred to the vinyl position. In contrast, when an alkynyl tin reagent was employed, the alkynylation took place at the vinyl position, with the deuterium atom retained on the phenyl ring (Scheme 26, top). 


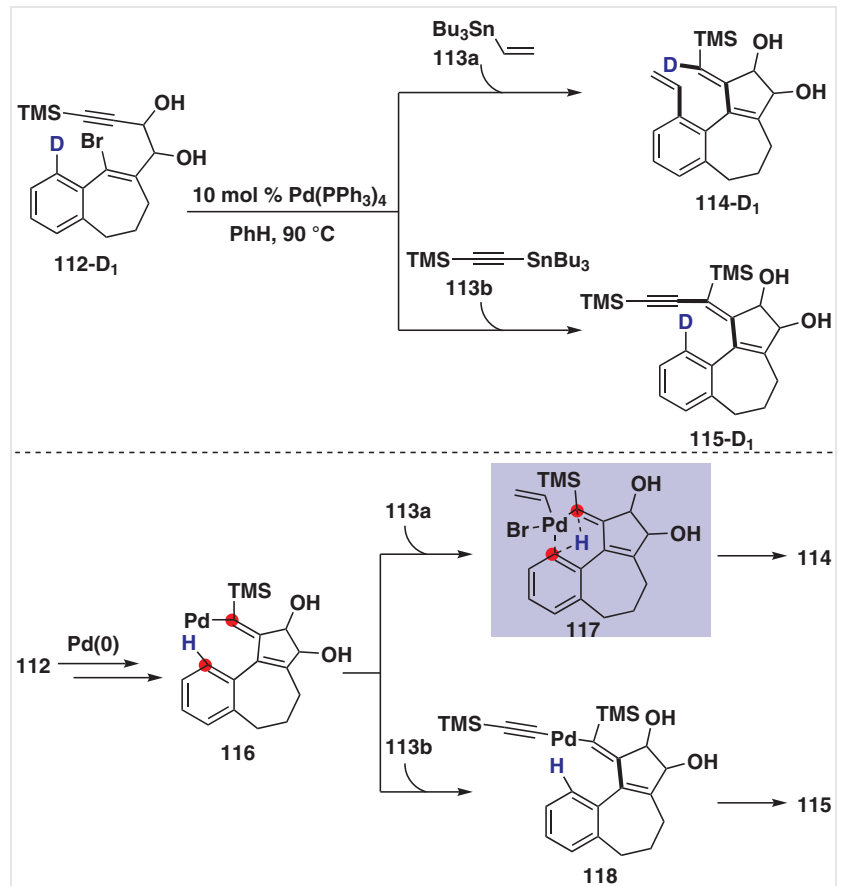

Scheme 26 Palladium-catalyzed intramolecular alkyne bridging $\mathrm{C}-\mathrm{H}$ activation/Stille cross-coupling

Based on this intriguing observation, a plausible mechanism was proposed (Scheme 26, bottom). The process was initiated by oxidative addition of the palladium(0) catalyst to vinyl bromide 112. Next, syn cyclocarbopalladation of the tethered triple bond would give vinyl palladium(II) species 116, a process which can be referred to as the alkyne bridging process. At this stage, the destiny of intermediate 116 was determined by the type of tin reagent involved. When a vinyl tin reagent was used, selective hydrogen abstraction would take place followed by transmetalation with the vinyl tin reagent to give the six-membered palladacycle 117. Hence this pathway accounts for the vinylation on the phenyl ring to form 114. In contrast, when a stannylated alkyne was utilized, the selective formation of $\mathbf{1 1 5}$ was observed. The authors performed DFT calculations on the pathway to form 114, which revealed that a vinyl to aryl 1,5 -palladium shift and a $\operatorname{Pd}(0) / \operatorname{Pd}(\mathrm{II})$ redox cycle were involved in the pathway. ${ }^{48}$

Mechanistically similar to Hu's work on alkyne bridging C-H activation, ${ }^{46}$ Werz and co-workers designed a palladium-catalyzed benzene annulation for the synthesis of chromanes and isochromanes. ${ }^{49}$ In this work, 2-bromoglycal 119, with an appropriate alkyne tether, was employed as the model substrate for reactions with a variety of symmet- ric internal alkynes 74. As depicted, the alkyne bridging process probably takes place via a two-fold carbopalladation pathway to give the vinyl palladium(II) species 121. Subsequent $\mathrm{C}-\mathrm{H}$ bond activation could then afford a sevenmembered palladacycle 122, which upon reductive elimination leads to the formation of chromane derivatives $\mathbf{1 2 0}$ (Scheme 27, top). By slight variation of the structure of the reactant, isochromane derivatives could also be prepared in a straightforward manner under the standard conditions. This strategy has also been applied for the synthesis of naphthalene derivatives by the same group (Scheme 27, bottom). ${ }^{50}$
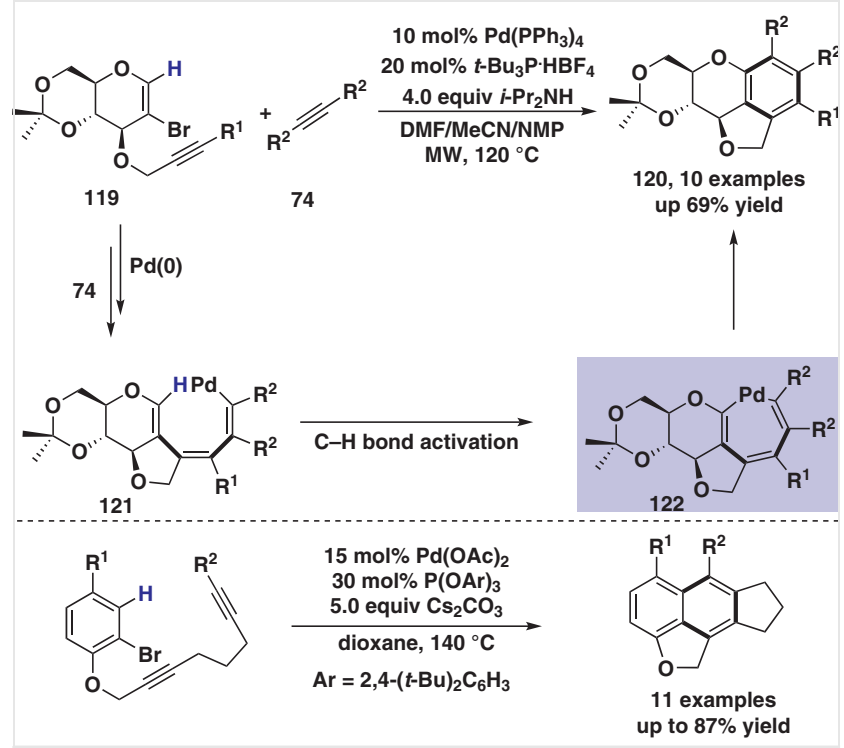

Scheme 27 Palladium-catalyzed cascade reaction for benzene annulation via intramolecular alkyne bridging $\mathrm{C}-\mathrm{H}$ bond activation

Very recently, Luan and co-workers examined the reactivity of the five-membered palladacycle 127, (see Scheme 28), generated through intramolecular alkyne bridging $\mathrm{C}-\mathrm{H}$ activation, toward several bifunctional reagents (Figure 1), including 1-bromo-2-naphthol (123a), o-bromophenols 123b, $p$-bromophenols 123c, ethyl 2-(4-bromonaphthalen1 -yl)acetate (123d) and benzoyl O-substituted hydroxylamine 123e. ${ }^{51}$



Figure 1 Structures of bifunctional reagents 123 


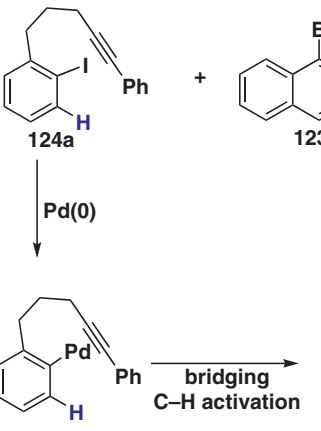

126a

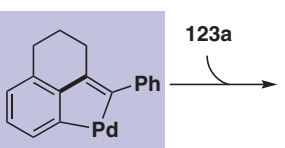

$127 \mathrm{a}$

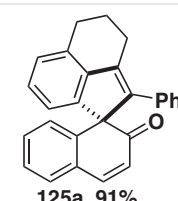
$0 \mathrm{~mol} \% \mathrm{Pd}(\mathrm{OAc})_{2}$ 2.0 equiv $\mathrm{Cs}_{2} \mathrm{CO}_{3}$ DMF, $130{ }^{\circ} \mathrm{C}$

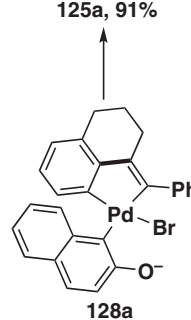

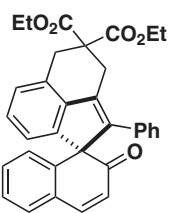

$83 \%$

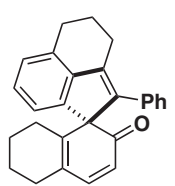

$82 \%$

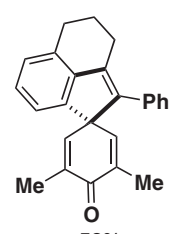

$56 \%$

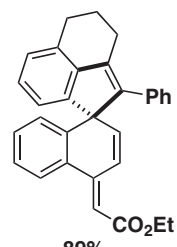

$89 \%$
Scheme 28 Synthesis of spirocyclic products $\mathbf{1 2 5}$ through palladiumcatalyzed intramolecular alkyne bridging $\mathrm{C}-\mathrm{H}$ activation

For the palladium-catalyzed reactions of aryl iodides $\mathbf{1 2 4}$ with alkynes $\mathbf{1 2 3 a} \mathbf{a}-\mathbf{d}$, dearomatization of $\mathbf{1 2 3}$ to form a range of spiro products $\mathbf{1 2 5}$ was observed. ${ }^{51 a}$ This reaction was operationally simple, and required no external ligands, while exhibiting broad substrate scope (53 examples). The products 125 were obtained in moderate to excellent yields (48-92\%). Herein we take the reaction of 124a with 123a as an example to explain the mechanism based on the results obtained by Luan and co-workers. In analogy with the aforementioned alkyne bridging $\mathrm{C}-\mathrm{H}$ activation, the reaction started with oxidative addition of the in situ generated palladium(0) catalyst to alkyne 124a. Intramolecular syn carbopalladation of the resulting intermediate 126a produced a vinyl palladium(II) species. The key intermediate 127a was formed by intramolecular $\mathrm{C}-\mathrm{H}$ palladation. At this stage, additional oxidative addition of 127a to 123a would generate the palladium(IV) species 128a. Finally, a two-fold reductive elimination of 128a involving dearomatization of the naphthalene ring would eventually give the final spiro product 125a (Scheme 28).

In their subsequent study, Luan and co-workers identified that hydroxylamine derivative 123 e could act as an excellent bifunctional nitrogen source in the reaction with transient palladacycle $\mathbf{1 2 7}$, providing a rapid access to diverse tricyclic indole scaffolds. ${ }^{51 b}$ Based on their comprehensive mechanistic studies, two plausible reaction pathways were proposed. Coordination of deprotonated 123e to the electrophilic palladium intermediate 127a could furnish another five-membered palladacycle 130. For pathway a, a concerted 1,2-aryl migration from the palladium atom to the nitrogen center would lead to the formation of six-

membered aza-palladacycle 131. Alternatively, the formation of a putative Pd-nitrene species $\mathbf{1 3 2}$ was also equally reasonable to explain the reaction outcome. Migratory insertion of the aryl moiety could furnish intermediate $\mathbf{1 3 1}$ as well (pathway b). Reductive elimination of 131 would afford tricyclic indole 129a as the final product and release the active palladium catalyst (Scheme 29, top). Again, this reaction displayed a very broad substrate scope (more than 50 examples). It is noteworthy to mention that the linker on the phenyl ring was not restricted to the ortho position with respect to the iodide moiety. Substrates with an appropriate alkynyl linker located at meta or para positions were viable reactants. This strategy has been applied for the construction of a variety of macrocycle-embedded indole derivatives 129 (Scheme 29, bottom). Almost at the same time, Zhang and co-workers reported a similar tricyclic indole synthesis by applying a comparable strategy, but using $\mathrm{N}, \mathrm{N}$-di-tert-butyldiaziridinone $\mathbf{4 9}$ as the amination reagent. $^{52}$
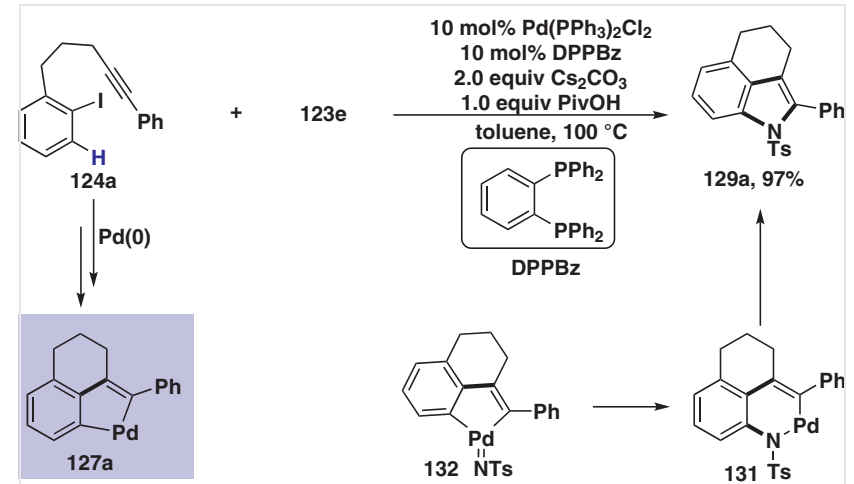
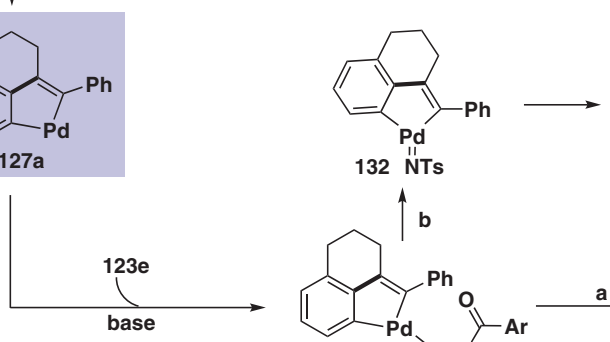

132 NTs

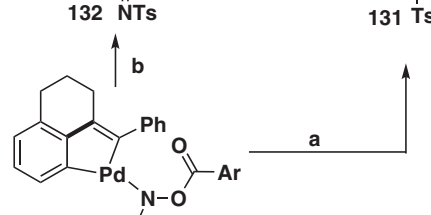

130 Ts'

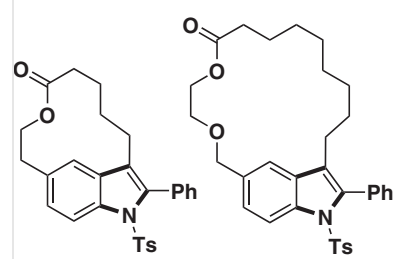

$21 \%(92 \%)^{a}$

$69 \%(95 \%)^{a}$

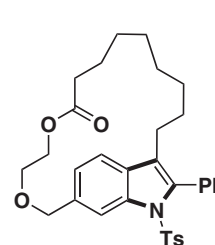

$73 \%(97 \%)^{\mathrm{a}}$

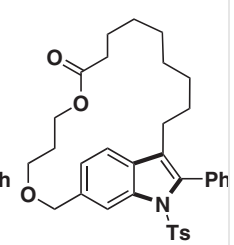

$64 \%(95 \%)^{a}$

a Yield based on recovered starting material in parentheses.

Scheme 29 Synthesis of tricyclic indoles 129 through palladium-catalyzed intramolecular alkyne bridging $\mathrm{C}-\mathrm{H}$ activation

Recently, Shintani and co-workers described an intramolecular alkyne bridging $\mathrm{C}-\mathrm{H}$ activation via a 1,4-palladium shift with a concomitant double bond isomerization from the $E$-isomer to the $Z$-isomer. ${ }^{53}$ Specifically, oxidative addition of 133 to the active palladium $(0)$ catalyst could provide palladium(II) intermediate 135 (Scheme 30). 
Migratory insertion of the tethered alkyne moiety would furnish a vinyl palladium(II) species $\mathbf{1 3 6}$, which was ready to undergo a 1,4-palladium shift to generate another aryl palladium(II) species 138 through two interconvertible fivemembered palladacycles 137 and 137'. Deuterium labeling experiments indicated that the proton located at the vinyl position in $\mathbf{1 3 8}$ was derived from an external hydrogen donor other than the hydrogen atom from the aryl ring $\left(\operatorname{Ar}^{1}\right)$. Additional mechanistic studies by synthesis of plausible intermediates supported the involvement of palladium(II) species 138 and its $E$-isomer 138'. Finally, C-H bond activation in 138 and subsequent reductive elimination of the potential seven-membered palladacycle gave the product benzophenanthroline 134.

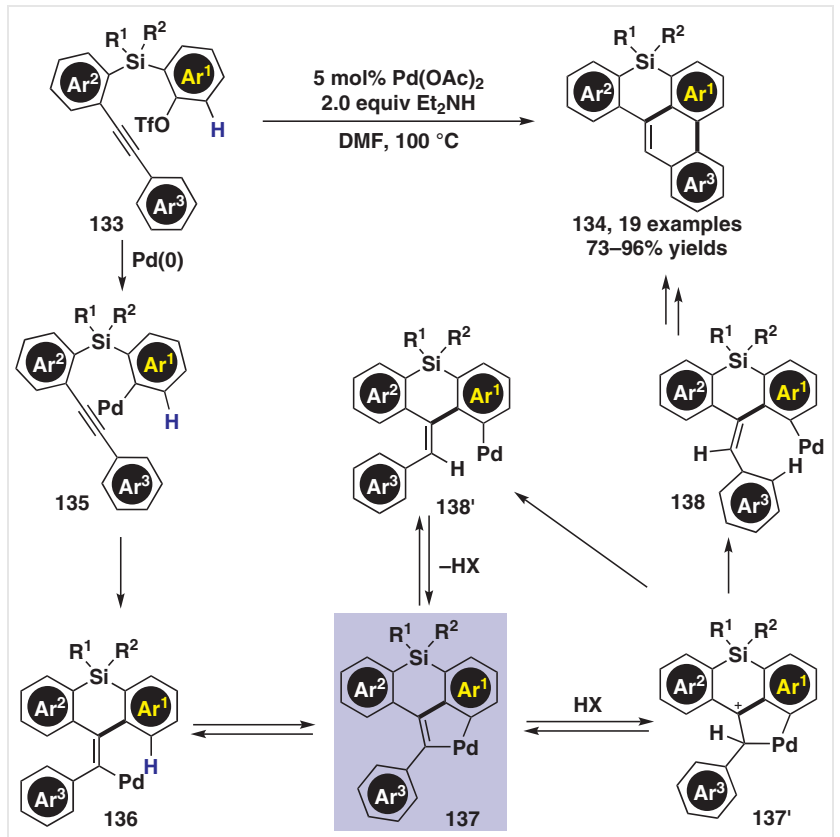

Scheme 30 Benzophenanthroline synthesis via intramolecular alkyne bridging $\mathrm{C}-\mathrm{H}$ activation and a 1,4-palladium shift

\section{Palladium-Catalyzed Carbene Bridging C-H Activation}

The extrusion of dinitrogen from diazo compounds in the presence of an appropriate transition-metal catalyst has been considered as a reliable method to generate reactive metal carbene intermediates. ${ }^{1 e, 54}$ In the past decade, studies on metal carbenes participating in inert $\mathrm{C}-\mathrm{H}$ bond functionalization has attracted much attention. ${ }^{55}$ When considering the mechanistic pathway, for the majority of the developed reactions, inert $\mathrm{C}-\mathrm{H}$ bond metalation takes place prior to metal carbene formation. In this section, we will fo-

cus on the recent progress made on palladium carbenes ${ }^{56}$ participated $\mathrm{C}-\mathrm{H}$ bond activation with a well-defined mechanistic perspective in which the elementary step of $\mathrm{C}-\mathrm{H}$ activation proceeds after palladium carbene formation. ${ }^{57}$ In other words, without formation of a carbene intermediate, the $\mathrm{C}-\mathrm{H}$ activation event would not occur.

In 2018, Huang and co-workers reported a palladiumcatalyzed intermolecular acylation of aryl diazoesters 139 with ortho-bromobenzaldehyde (73b). ${ }^{58}$ Inspired by the work of Heck and co-workers on indenone synthesis, ${ }^{26}$ Huang conceived a novel reaction mode for the metal carbene participated $\mathrm{C}-\mathrm{H}$ bond activation. In detail, oxidative addition of the low valent palladium $(0)$ catalyst to $\mathbf{7 3}$ could give the palladium(II) species 76. According to the conventional metal carbene participated reactions, $\mathrm{C}-\mathrm{H}$ bond palladation would proceed first. However, due to the high strain energy, the formation of benzopalladabutenone 141 was unlikely. Hence, $\mathbf{7 6}$ was expected to react with aryl diazoester 139 to form the palladium carbene intermediate 142. Migratory insertion of $\mathbf{1 4 2}$ and subsequent isomerization would furnish the palladium(II) enolate 143. At this stage, $\mathrm{C}-\mathrm{H}$ bond palladation with the proximal aldehyde tether would be facile, and a seven-membered palladacycle 144 could be produced. In subsequent studies of this reaction, Huang and co-workers referred to the whole process from 76 to 144 as carbene bridging $\mathrm{C}-\mathrm{H}$ activation (CBA). ${ }^{59}$ Reductive elimination of $\mathbf{1 4 4}$ would give the final isocoumarin derivatives 140 (Scheme 31). Huang also performed DFT calculations to understand the reaction mechanism, which provided a reasonable energy profile that supported the CBA pathway.

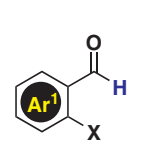

73, $\mathrm{X}=$

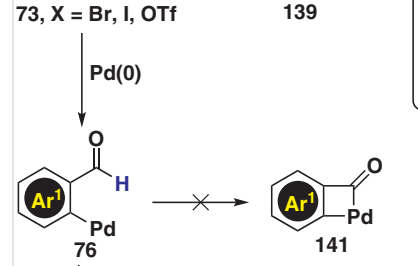

$139 \mid \begin{aligned} & \text { carbene } \\ & \text { bridging }\end{aligned}$

${ }_{142}{ }_{\mathrm{Ar}^{2}}^{\mathrm{Pd}} \mathrm{CO}_{2} \mathrm{R}$

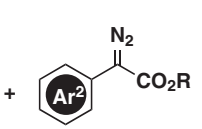

139

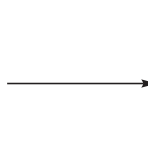

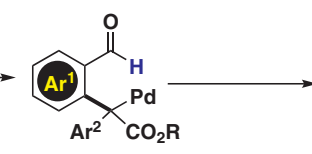

Scheme 31 Palladium-catalyzed isocoumarin synthesis via carbene bridging $\mathrm{C}-\mathrm{H}$ bond activation 


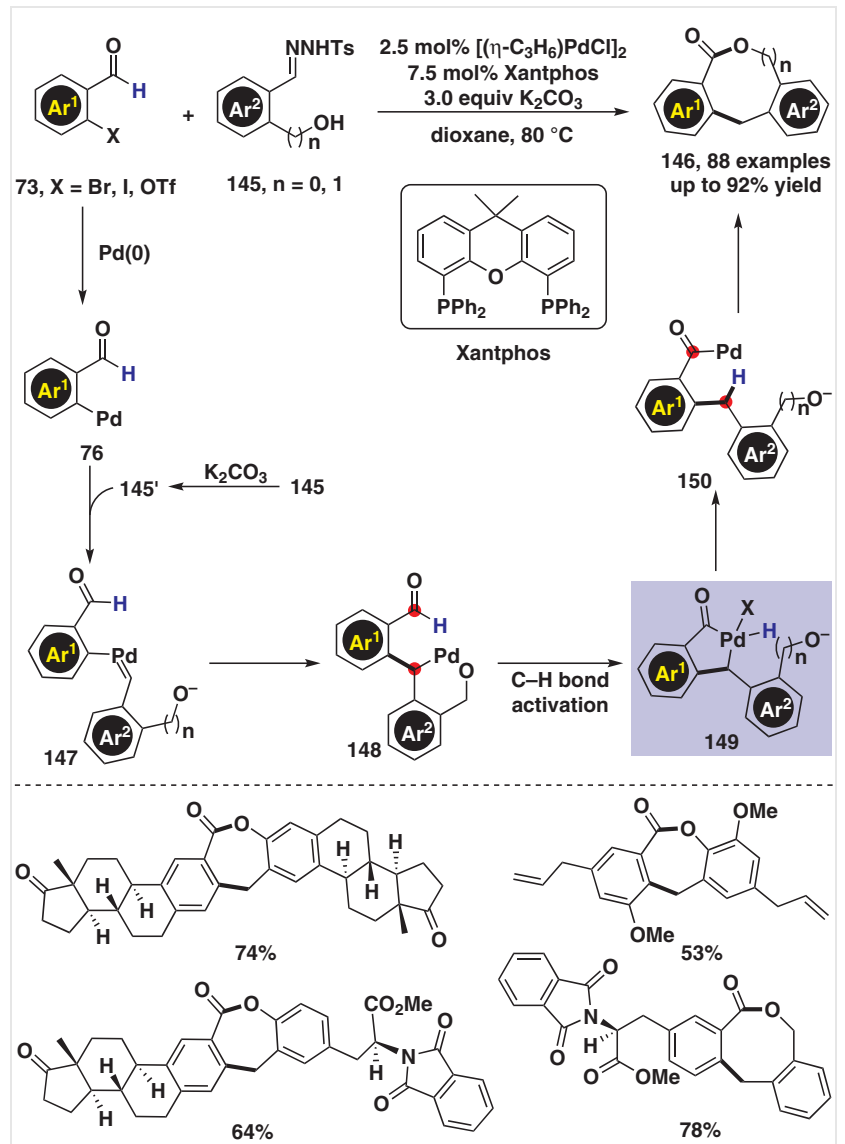

Scheme 32 Palladium-catalyzed medium-sized lactone synthesis via carbene bridging $\mathrm{C}-\mathrm{H}$ bond activation

Encouraged by the aforementioned work, Huang and co-workers applied their CBA strategy for the synthesis of seven- and eight-membered lactones. ${ }^{60}$ As demonstrated in Scheme 32, $\mathrm{N}$-tosylhydrazones 145 derived from salicylaldehyde analogs were selected as the precursors of bifunctional diazo compounds to react with benzaldehydes $\mathbf{7 3}$. This reaction displayed very broad substrate scope. By variation of the carbene precursors 145 , besides seven-membered lactones, synthetically more challenging eight-membered lactones could be prepared in a modular fashion. The employment of ortho-formyl aryl triflates as reactants was noteworthy, as formal dimerization of the salicylaldehyde analogs could be achieved. Moreover, substrates containing pharmacophoric fragments could be coupled with high efficiency. Based on deuterium experiments and DFT calculations, a CBA pathway was proposed by the authors. Akin to their previous study, the reaction involved oxidative addition and palladium carbene $\mathbf{1 4 7}$ formation. Migratory insertion of 147 could afford intermediate $\mathbf{1 4 8}$, which was setup to undergo a 1,4-palladium shift, probably through five-membered palladacycle 149 , to give acyl palladium(II) species 150. Ring closure of $\mathbf{1 5 0}$ would give the final medium-sized lactones 146.
Tricyclic ring systems possessing a dibenzo structure joined to a seven-membered heterocyclic ring often show important biological activities. However, a brief survey of the literature revealed that a modular approach to such compounds based on an efficient intermolecular reaction of readily available substrates was lacking. As part of further studies on palladium carbene bridging $\mathrm{C}-\mathrm{H}$ activation, Huang and co-workers developed a modular approach to construct dibenzo-fused $\varepsilon$-lactams 152 by using $o$-(pseudo)halo arylaldehydes $\mathbf{7 3}$ and $\mathrm{N}$-tosylhydrazones $\mathbf{1 5 1}$ as reactants (Scheme 33). ${ }^{61}$ Again, this reaction exhibited broad substrate scope (52 examples, up to $97 \%$ isolated yield) and good functional group compatibility. Moreover, the same group have applied this protocol as a key step for the synthesis of several bioactive molecules.

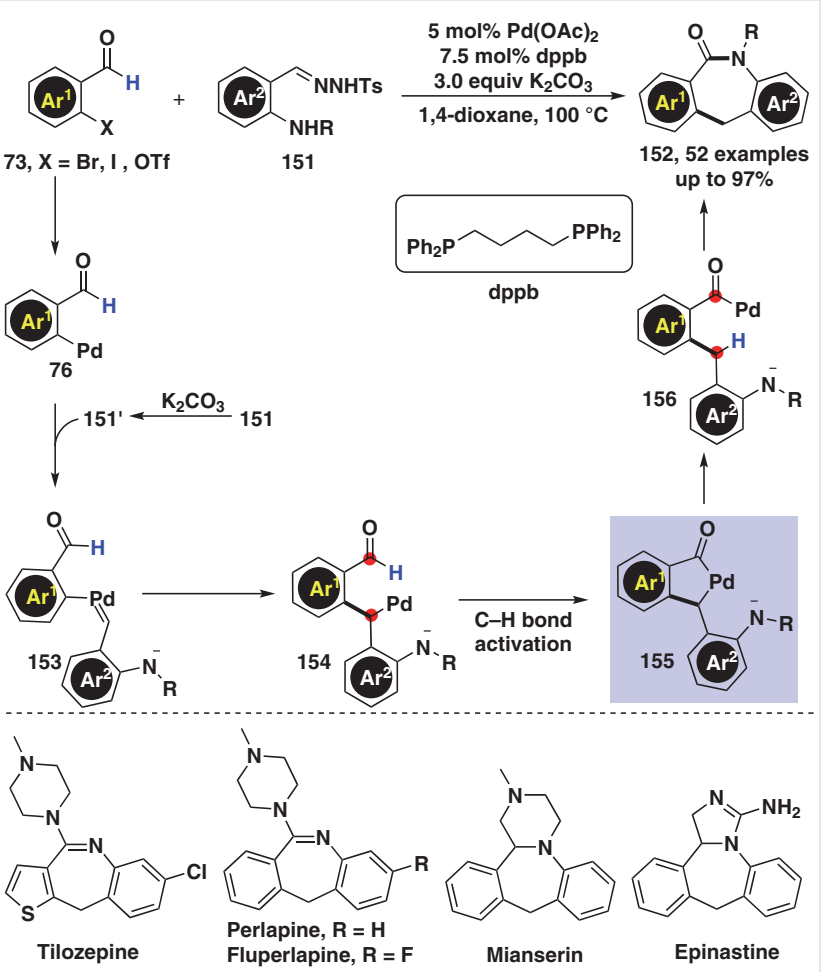

Scheme 33 Palladium-catalyzed synthesis of dibenzo-fused $\varepsilon$-lactams via carbene bridging $\mathrm{C}-\mathrm{H}$ bond activation

Inspired by these studies, Huang and co-workers conceived that the transient palladacycle $\mathbf{1 4 9}$ might be trapped by a suitable external nucleophile. Based on this rationale, Huang has very recently reported a palladium-catalyzed three-component reaction of $o$-bromobenzaldehydes 73, $N$ tosylhydrazones 157 and methanol to give methyl 2-benzoylbenzoates 158. ${ }^{62}$ It was found that the employment of methanol as the reaction medium was essential to achieve high yields of 158. Furthermore, according to their DFT calculations, a different mechanistic pathway was proposed. ${ }^{63}$ Namely, after the carbene bridging process, palladium(II) 
species 159 could transmetalate with methanol to give intermediate 160. A subsequent methoxy group transfer from the palladium center to the tethered aldehyde moiety could furnish hemiacetal 161. Selective hydrogen atom migration would generate the palladium hydride species 162 , which upon reductive elimination would give the desired product 158 (Scheme 34, top). More interestingly, the choice of ligand not only controlled the chemoselectivity of the whole reaction, but also altered the pathway for the formation of 158. For example, when the sterically hindered phosphine ligand $\mathrm{P}(\mathrm{o} \text {-tolyl })_{3}$ was employed, methyl ether $163 \mathrm{~b}$ was obtained as the major product ( $80 \%$ yield, Scheme 34 , bottom). According to the energetics, the minor product $\mathbf{1 5 8 b}$ (9\% yield) was probably produced through a CBA pathway analogous to that shown in Scheme 32.

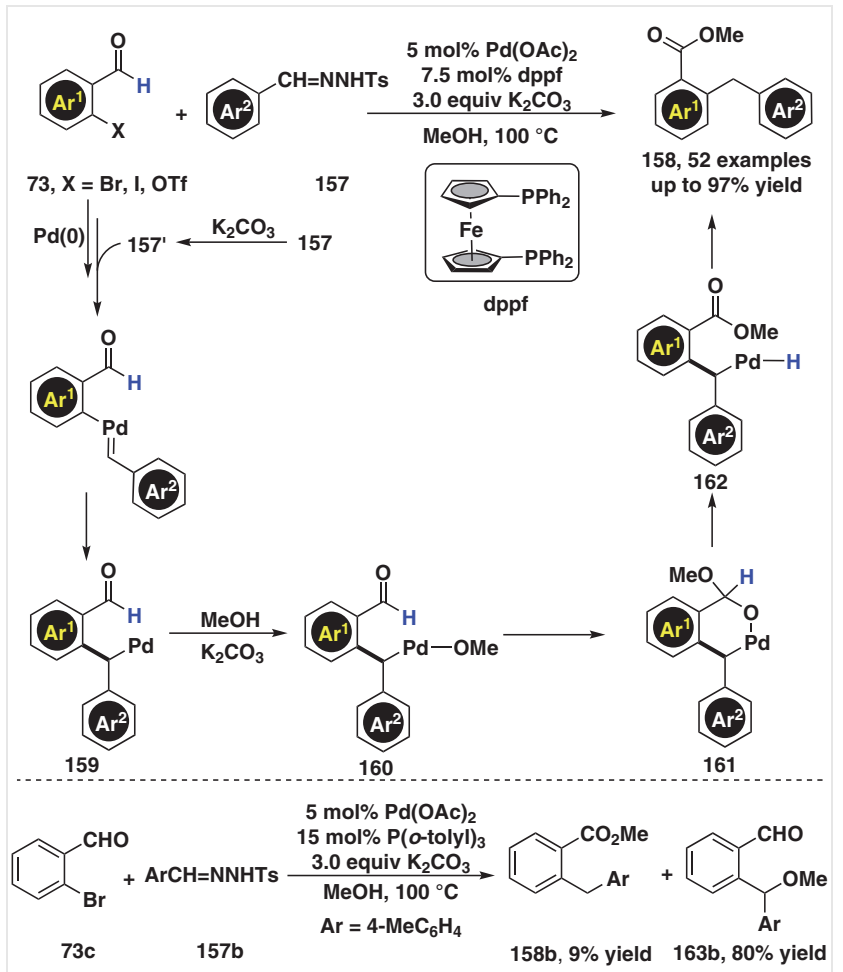

Scheme 34 Palladium-catalyzed three-component coupling reaction of o-bromobenzaldehydes, $\mathrm{N}$-tosylhydrazones, and methanol

\section{Conclusion and Outlook}

As outlined in this short review, it is apparent that bridging $\mathrm{C}-\mathrm{H}$ activation offers valuable methods to functionalize inert $\mathrm{C}-\mathrm{H}$ bonds in simple molecules. The introduction of appropriate bridging reagents not only facilitates proximal $\mathrm{C}-\mathrm{H}$ bond activation, but also increases the structural complexities of the products. According to the general principles of such methods, we anticipate that transitionmetal catalysts other than palladium may be applicable for such transformations. On the other hand, as can be seen from the advances summarized here, only a few types of compounds are suitable as bridging reagents. Therefore, highly efficient catalytic systems remain to be developed in the future so that a wider range of feedstock chemicals can be employed as bridging reagents.

\section{Funding Information}

We are grateful for financial support from the National Natural Science Foundation of China (NSFC) (Grant Nos. 21402197, 21871259, and 21901244), the Hundred Talents Program, and the Strategic Priority Research Program of the Chinese Academy of Sciences (Grant No. XDB20000000).

\section{References}

(1) (a) Jia, C.; Kitamura, T.; Fujiwara, Y. Acc. Chem. Res. 2001, 34, 633. (b) Godula, K.; Sames, D. Science 2006, 312, 67. (c) DiazRequejo, M. M.; Perez, P. J. Chem. Rev. 2008, 108, 3379. (d) Giri, R.; Shi, B. F.; Engle, K. M.; Maugel, N.; Yu, J. Q. Chem. Soc. Rev. 2009, 38, 3242. (e) Doyle, M. P.; Duffy, R.; Ratnikov, M.; Zhou, L. Chem. Rev. 2010, 110, 704. (f) Ackermann, L. Chem. Rev. 2011, 111, 1315. (g) Wencel-Delord, J.; Droge, T.; Liu, F.; Glorius, F. Chem. Soc. Rev. 2011, 40, 4740. (h) Arockiam, P. B.; Bruneau, C.; Dixneuf, P. H. Chem. Rev. 2012, 112, 5879. (i) Yamaguchi, J.; Yamaguchi, A. D.; Itami, K. Angew. Chem. Int. Ed. 2012, 51, 8960. (j) Zhu, R. Y.; Farmer, M. E.; Chen, Y. Q.; Yu, J. Q. Angew. Chem. Int. Ed. 2016, 55, 10578. (k) Yang, Y.; Lan, J.; You, J. Chem. Rev. 2017, 117, 8787. (l) Wei, Y.; Hu, P.; Zhang, M.; Su, W. Chem. Rev. 2017, 117, 8864. (m) Newton, C. G.; Wang, S. G.; Oliveira, C. C.; Cramer, N. Chem. Rev. 2017, 117, 8908.

(2) (a) Ritleng, V.; Sirlin, C.; Pfeffer, M. Chem. Rev. 2002, 102, 1731. (b) Dupont, J.; Consorti, C. S.; Spencer, J. Chem. Rev. 2005, 105, 2527. (c) Lyons, T. W.; Sanford, M. S. Chem. Rev. 2010, 110, 1147. (d) Engle, K. M.; Mei, T. S.; Wasa, M.; Yu, J. Q. Acc. Chem. Res. 2012, 45, 788. (e) Topczewski, J. J.; Sanford, M. S. Chem. Sci. 2015, 6, 70. (f) Baudoin, O. Acc. Chem. Res. 2017, 50, 1114. (g) He, J.; Wasa, M.; Chan, K. S. L.; Shao, Q.; Yu, J. Q. Chem. Rev. 2017, 117,8754

(3) (a) McNally, A.; Haffemayer, B.; Collins, B. S.; Gaunt, M. J. Nature 2014, 510, 129. (b) He, C.; Gaunt, M. J. Angew. Chem. Int. Ed. 2015, 54, 15840. (c) Smalley, A. P.; Gaunt, M. J. J. Am. Chem. Soc. 2015, 137, 10632. (d) Willcox, D.; Chappell, B. G.; Hogg, K. F.; Calleja, J.; Smalley, A. P.; Gaunt, M. J. Science 2016, 354, 851. (e) He, C.; Gaunt, M. J. Chem. Sci. 2017, 8, 3586. (f) Hogg, K. F.; Trowbridge, A.; Alvarez-Pérez, A.; Gaunt, M. J. Chem. Sci. 2017, 8, 8198. (g) Smalley, A. P.; Cuthbertson, J. D.; Gaunt, M. J. J. Am. Chem. Soc. 2017, 139, 1412. (h) Wen, J.; Wang, D.; Qian, J.; Wang, D.; Zhu, C.; Zhao, Y.; Shi, Z. Angew. Chem. Int. Ed. 2019, 58, 2078. (i) Su, B.; Bunescu, A.; Qiu, Y.; Zuend, S. J.; Ernst, M.; Hartwig, J. F. J. Am. Chem. Soc. 2020, 142, 7912.

(4) (a) Jiao, L.; Bach, T. J. Am. Chem. Soc. 2011, 133, 12990. (b) Jiao, L.; Herdtweck, E.; Bach, T. J. Am. Chem. Soc. 2012, 134, 14563. (c) Jiao, L.; Bach, T. Angew. Chem. Int. Ed. 2013, 52, 6080. (d) Sui, X.; Zhu, R.; Li, G.; Ma, X.; Gu, Z. J. Am. Chem. Soc. 2013, 135, 9318. (e) Zhao, K.; Xu, S.; Pan, C.; Sui, X.; Gu, Z. Org. Lett. 2016, 18, 3782. (f) Li, R.; Zhou, Y.; Xu, X.; Dong, G. J. Am. Chem. Soc. 2019, 141, 18958. 
(5) (a) Wang, J.; Dong, Z.; Yang, C.; Dong, G. Nat. Chem. 2019, 11, 1106. (b) Wu, Z.; Fatuzzo, N.; Dong, G. J. Am. Chem. Soc. 2020, $142,2715$.

(6) (a) Catellani, M.; Motti, E.; Della Ca', N. Acc. Chem. Res. 2008, 41, 1512. (b) Chen, X.; Engle, K. M.; Wang, D. H.; Yu, J. Q. Angew. Chem. Int. Ed. 2009, 48, 5094. (c) Gu, Z.; Sui, X.; Zhu, R. Synlett 2013, 24, 2023. (d) Ye, J.; Lautens, M. Nat. Chem. 2015, 7, 863. (e) Della Ca', N.; Fontana, M.; Motti, E.; Catellani, M. Acc. Chem. Res. 2016, 49, 1389. (f) Kim, D. S.; Park, W. J.; Jun, C. H. Chem. Rev. 2017, 117, 8977. (g) Gandeepan, P.; Ackermann, L. Chem 2018, 4, 199. (h) Cheng, H. G.; Chen, S.; Chen, R.; Zhou, Q. Angew. Chem. Int. Ed. 2019, 58, 5832. (i) Wang, J.; Dong, G. Chem. Rev. 2019, 119, 7478.

(7) (a) Vlaar, T.; Ruijter, E.; Orru, R. V. A. Adv. Synth. Catal. 2011, 353, 809. (b) Mehta, V. P.; García-López, J.-A. ChemCatChem 2017, 9, 1149. (c) Ping, Y.; Li, Y.; Zhu, J.; Kong, W. Angew. Chem. Int. Ed. 2019, 58, 1562.

(8) Huang, Q.; Fazio, A.; Dai, G.; Campo, M. A.; Larock, R. C. J. Am. Chem. Soc. 2004, 126, 7460.

(9) (a) Ma, S.; Gu, Z. Angew. Chem. Int. Ed. 2005, 44, 7512. (b) Shi, F.; Larock, R. C. Top. Curr. Chem. 2010, 292, 123. (c) Rahim, A.; Feng, J.; Gu, Z. Chin. J. Chem. 2019, 37, 929.

(10) (a) Piou, T.; Bunescu, A.; Wang, Q.; Neuville, L.; Zhu, J. Angew. Chem. Int. Ed. 2013, 52, 12385. (b) Bunescu, A.; Piou, T.; Wang, Q.; Zhu, J. Org. Lett. 2015, 17, 334.

(11) Wang, M.; Zhang, X.; Zhuang, Y. X.; Xu, Y. H.; Loh, T. P. J. Am. Chem. Soc. 2015, 137, 1341.

(12) Lu, Z.; Hu, C.; Guo, J.; Li, J.; Cui, Y.; Jia, Y. Org. Lett. 2010, 12, 480.

(13) Sickert, M.; Weinstabl, H.; Peters, B.; Hou, X.; Lautens, M. Angew. Chem. Int. Ed. 2014, 53, 5147.

(14) He, H.-Y.; Wang, W.; Yu, X.-J.; Huang, J.; Jian, L.; Fu, H.-Y.; Zheng, X.-L.; Chen, H.; Li, R.-X. Eur. J. Org. Chem. 2016, 5616.

(15) Luo, X.; Xu, Y.; Xiao, G.; Liu, W.; Qian, C.; Deng, G.; Song, J.; Liang, Y.; Yang, C. Org. Lett. 2018, 20, 2997.

(16) (a) Wollenburg, M.; Bajohr, J.; Marchese, A. D.; Whyte, A.; Glorius, F.; Lautens, M. Org. Lett. 2020, 22, 3679. (b) Lu, H.; Yang, X.; Zhou, L.; Li, W.; Deng, G.; Yang, Y.; Liang, Y. Org. Chem. Front. 2020, 7, 2016.

(17) Yao, T.; He, D. Org. Lett. 2017, 19, 842.

(18) Yoon, H.; Lossouarn, A.; Landau, F.; Lautens, M. Org. Lett. 2016, $18,6324$.

(19) Luo, X.; Zhou, L.; Lu, H.; Deng, G.; Liang, Y.; Yang, C.; Yang, Y. Org. Lett. 2019, 21, 9960.

(20) Rodriguez, J. F.; Marchese, A. D.; Lautens, M. Org. Lett. 2018, 20, 4367.

(21) Yoon, H.; Rolz, M.; Landau, F.; Lautens, M. Angew. Chem. Int. Ed. 2017, 56, 10920.

(22) Zheng, H.; Zhu, Y.; Shi, Y. Angew. Chem. Int. Ed. 2014, 53, 11280.

(23) (a) Mauleón, P.; Alonso, I.; Carretero, J. C. Angew. Chem. Int. Ed. 2001, 40 , 1291. (b) Mauleon, P.; Nunez, A. A.; Alonso, I.; Carretero, J. C. Chem. Eur. J. 2003, 9, 1511. (c) Alonso, I.; Alcami, M.; Mauleon, P.; Carretero, J. C. Chem. Eur. J. 2006, 12, 4576.

(24) (a) Hu, Y.; Song, F.; Wu, F.; Cheng, D.; Wang, S. Chem. Eur. J. 2008, 14, 3110. (b) Hu, Y.; Yu, C.; Ren, D.; Hu, Q.; Zhang, L.; Cheng, D. Angew. Chem. Int. Ed. 2009, 48, 5448. (c) Hu, Y.; Ouyang, Y.; Qu, Y.; Hu, Q.; Yao, H. Chem. Commun. 2009, 4575. (d) Hu, Y.; Qu, Y.; Wu, F.; Gui, J.; Wei, Y.; Hu, Q.; Wang, S. Chem. Asian J. 2010, 5, 309. (e) Hu, Y.; Ren, D.; Zhang, L.; Lin, X.; Wan, J. Eur. J. Org. Chem. 2010, 4454.

(25) Ohno, H.; Miyamura, K.; Mizutani, T.; Kadoh, Y.; Takeoka, Y.; Hamaguchi, H.; Tanaka, T. Chem. Eur. J. 2005, 11, 3728.

(26) Tao, W.; Silverberg, L. J.; Rheingold, A. L.; Heck, R. F. Organometallics 1989, 8, 2550.
(27) Larock, R. C.; Doty, M. J.; Cacchi, S. J. Org. Chem. 1993, 58, 4579.

(28) Ramesh, K.; Satyanarayana, G. Eur. J. Org. Chem. 2018, 2018, 4135.

(29) (a) Zhang, X.; Larock, R. C. Org. Lett. 2005, 7, 3973. (b) Waldo, J. P.; Zhang, X.; Shi, F.; Larock, R. C. J. Org. Chem. 2008, 73, 6679.

(30) Sakakibara, T.; Tanaka, Y.; Yamasaki, S.-i. Chem. Lett. 1986, 15, 797.

(31) Kawasaki, S.; Satoh, T.; Miura, M.; Nomura, M. J. Org. Chem. 2003, 68, 6836.

(32) (a) Dyker, G. J. Org. Chem. 1993, 58, 234. (b) Dyker, G.; Kellner, A. Tetrahedron Lett. 1994, 35, 7633.

(33) (a) Tian, Q.; Larock, R. C. Org. Lett. 2000, 2, 3329. (b) Larock, R. C.; Tian, Q. J. Org. Chem. 2001, 66, 7372.

(34) Zhou, B.; Lu, A.; Shao, C.; Liang, X.; Zhang, Y. Chem. Commun. 2018, 54, 10598.

(35) Zhou, B.; Wu, Z.; Ma, D.; Ji, X.; Zhang, Y. Org. Lett. 2018, 20, 6440.

(36) Jafarpour, F.; Ghasemi, M.; Mohaghegh, F.; Asgari, S.; Habibi, A. Org. Lett. 2019, 21, 10143.

(37) Zhou, B.; Wu, Z.; Qi, W. X.; Sun, X. L.; Zhang, Y. H. Adv. Synth. Catal. 2018, 360, 4480.

(38) Yang, Y.; Zhou, L.; Yang, X.; Luo, X.; Deng, G.; Yang, Y.; Liang, Y. Synthesis 2020, 52, 1223.

(39) Yamamoto, Y.; Jiang, J.; Yasui, T. Chem. Eur. J. 2020, 26, 3749.

(40) (a) Liu, Z.; Zhang, X.; Larock, R. C. J. Am. Chem. Soc. 2005, 127, 15716. (b) Liu, Z.; Larock, R. C. J. Org. Chem. 2007, 72, 223. (c) Liu, Z.; Larock, R. C. Angew. Chem. Int. Ed. 2007, 46, 2535.

(41) Jayanth, T. T.; Cheng, C. H. Chem. Commun. 2006, 894.

(42) Zhao, J.; Campo, M.; Larock, R. C. Angew. Chem. Int. Ed. 2005, 44, 1873.

(43) (a) Zhao, J.; Larock, R. C. Org. Lett. 2005, 7, 701. (b) Zhao, J.; Larock, R. C. J. Org. Chem. 2006, 71, 5340.

(44) Ge, Y.; Zhang, J.; Qiu, Z.; Xie, Z. Angew. Chem. Int. Ed. 2020, 59, 4851.

(45) Guo, S.; Li, P.; Guan, Z.; Cai, L.; Chen, S.; Lin, A.; Yao, H. Org. Lett. 2019, 21, 921.

(46) (a) Hu, Y.; Yao, H.; Sun, Y.; Wan, J.; Lin, X.; Zhu, T. Chem. Eur. J. 2010, 16, 7635. (b) Hu, Y.; Zhu, T.; Mu, X.; Zhao, Q.; Yu, T.; Wen, L.; Zhang, Y.; Wu, M.; Zhang, H. Tetrahedron 2012, 68, 311.

(47) Bour, C.; Suffert, J. Org. Lett. 2005, 7, 653.

(48) Mota, A. J.; Dedieu, A.; Bour, C.; Suffert, J. J. Am. Chem. Soc. 2005, $127,7171$.

(49) Leibeling, M.; Milde, B.; Kratzert, D.; Stalke, D.; Werz, D. B. Chem. Eur. J. 2011, 17, 9888.

(50) Leibeling, M.; Pawliczek, M.; Kratzert, D.; Stalke, D.; Werz, D. B. Org. Lett. 2012, 14, 346

(51) (a) Zuo, Z.; Wang, J.; Liu, J.; Wang, Y.; Luan, X. Angew. Chem. Int. Ed. 2020, 59, 653. (b) Fan, L.; Hao, J.; Yu, J.; Ma, X.; Liu, J.; Luan, X. J. Am. Chem. Soc. 2020, 142, 6698.

(52) Cheng, C.; Zuo, X.; Tu, D.; Wan, B.; Zhang, Y. Org. Lett. 2020, 22, 4985.

(53) Tsuda, T.; Kawakami, Y.; Choi, S. M.; Shintani, R. Angew. Chem. Int. Ed. 2020, 59, 8057.

(54) (a) Doyle, M. P. Chem. Rev. 1986, 86, 919. (b) Ye, T.; McKervey, M. A. Chem. Rev. 1994, 94, 1091. (c) Padwa, A.; Weingarten, M. D. Chem. Rev. 1996, 96, 223. (d) Doyle, M. P.; Forbes, D. C. Chem. Rev. 1998, 98, 911. (e) Zhang, Z. H.; Wang, J. B. Tetrahedron 2008, 64, 6577. (f) Ford, A.; Miel, H.; Ring, A.; Slattery, C. N.; Maguire, A. R.; McKervey, M. A. Chem. Rev. 2015, 115, 9981. (g) Liu, L.; Zhang, J. Chem. Soc. Rev. 2016, 45, 506. (h) Cheng, Q. Q.; Deng, Y.; Lankelma, M.; Doyle, M. P. Chem. Soc. Rev. 2017, 46, 5425. (i) Zhu, D.; Chen, L.; Fan, H.; Yao, Q.; Zhu, S. Chem. Soc. Rev. 2020, 49, 908 . 
Synthesis

(55) (a) Hu, F.; Xia, Y.; Ma, C.; Zhang, Y.; Wang, J. Chem. Commun. 2015, 51, 7986. (b) Xiang, Y. Y.; Wang, C.; Ding, Q. P.; Peng, Y. Y. Adv. Synth. Catal. 2019, 361, 919.

(56) (a) Zhang, Y.; Wang, J. B. Eur. J. Org. Chem. 2011, 1015. (b) Zhang, Z.; Zhang, Y.; Wang, J. ACS Catal. 2011, 1, 1621. (c) Barluenga, J.; Valdes, C. Angew. Chem. Int. Ed. 2011, 50, 7486. (d) Shao, Z.; Zhang, H. Chem. Soc. Rev. 2012, 41, 560. (e) Xiao, Q.; Zhang, Y.; Wang, J. Acc. Chem. Res. 2013, 46, 236. (f) Xia, Y.; Wang, J. Chem. Soc. Rev. 2017, 46, 2306. (g) Xia, Y.; Qiu, D.; Wang, J. Chem. Rev. 2017, 117, 13810. (h) Xia, Y.; Wang, J. J. Am. Chem. Soc. 2020, $142,10592$.

(57) Xu, S.; Chen, R.; Fu, Z.; Zhou, Q.; Zhang, Y.; Wang, J. ACS Catal. 2017, 7, 1993.
(58) Yu, Y.; Lu, Q.; Chen, G.; Li, C.; Huang, X. Angew. Chem. Int. Ed. 2018, 57, 319.

(59) Yan, C.; Yu, Y. H.; Peng, B.; Huang, X. L. Eur. J. Org. Chem. 2020, 723.

(60) Yu, Y.; Chakraborty, P.; Song, J.; Zhu, L.; Li, C.; Huang, X. Nat. Commun. 2020, 11, 461.

(61) Yu, Y.; Ma, L.; Xia, J.; Xin, L.; Zhu, L.; Huang, X. Angew. Chem. Int. Ed. 2020, 59, in press; DOI: 10.1002/anie.202007799.

(62) Zhu, L.; Ren, X.; Yu, Y.; Ou, P.; Wang, Z. X.; Huang, X. Org. Lett. 2020, 22, 2087.

(63) Ren, X.; Zhu, L.; Yu, Y.; Wang, Z. X.; Huang, X. Org. Lett. 2020, 22, 3251. 